\title{
Fabrication of Biodegradable Polyester Nanocomposites by Electrospinning for Tissue Engineering
}

\author{
Zhi-Cai Xing, Seung-Jin Han, Yong-Suk Shin, and Inn-Kyu Kang \\ Department of Polymer Science and Engineering, Kyungpook National University, Daegu 702-701, Republic of Korea \\ Correspondence should be addressed to Inn-Kyu Kang, ikkang@knu.ac.kr
}

Received 1 October 2010; Accepted 28 January 2011

Academic Editor: Xiaojun Yu

Copyright () 2011 Zhi-Cai Xing et al. This is an open access article distributed under the Creative Commons Attribution License, which permits unrestricted use, distribution, and reproduction in any medium, provided the original work is properly cited.

Recently, nanocomposites have emerged as an efficient strategy to upgrade the structural and functional properties of synthetic polymers. Polyesters have attracted wide attention because of their biodegradability and biocompatibility. A logic consequence has been the introduction of natural extracellular matrix (ECM) molecules, organic or inorganic nanostructures to biodegradable polymers to produce nanocomposites with enhanced properties. Consequently, the improvement of the interfacial adhesion between biodegradable polymers and natural ECM molecules or nanostructures has become the key technique in the fabrication of nanocomposites. Electrospinning has been employed extensively in the design and development of tissue engineering scaffolds to generate nanofibrous substrates of synthetic biodegradable polymers and to simulate the cellular microenvironment. In this paper, several types of biodegradable polyester nanocomposites were prepared by electrospinning, with the aim of being used as tissue engineering scaffolds. The combination of biodegradable nanofibrous polymers and natural ECM molecules or nanostructures opens new paradigms for tissue engineering applications.

\section{Introduction}

Tissue engineering (TE) is a multidisciplinary field focused on the development and application of knowledge in engineering, life and clinical sciences for the solution of critical medical problems, such as tissue loss and organ failure [1]. It involves the fundamental understanding of structurefunction relationships in normal and pathological tissues and the development of biological substitutes that restore, maintain, or improve tissue function [2]. For in vitro engineering of living tissues, cultured cells are grown on bioactive degradable scaffolds that provide the physical and chemical cues to guide their proliferation, differentiation, and assembly into three-dimensional structures. One of the most critical issues in TE is the realization of scaffolds with specific physical, mechanical, and biological properties. Scaffolds act as a substrate for cellular growth, proliferation, and support for new tissue formation.

Materials used for TE applications must be designed to stimulate specific cell response at the molecular level. They should elicit specific interactions within cells and thereby direct cell attachment, proliferation, differentiation, and extracellular matrix production and organization. The selection of biomaterials constitutes a key point for the success of TE practice [3]. The fundamental requirements of the biomaterials used in tissue regeneration are to have biocompatible surfaces and have favorable mechanical properties. Conventional single polymer materials cannot satisfy these requirements. In fact, although various polymeric materials have been available and investigated for TE, no single biodegradable polymer can meet all of these requirements. Therefore, the design and preparation of the multicomponent polymer systems represent a viable strategy in order to develop innovative multifunctional biomaterials. In particular, the introduction of biomolecules or inorganic molecules into biodegradable polymer matrices is effective to obtain composites with specific properties.

Composite materials using synthetic and natural-based materials are increasingly proposed for biomedical applications [4-6]. Natural polymers such as collagen [7], chitosan [8], soy [9], alginate [10], silk [11], or starch [12] have already been proposed in many biomedical applications. The biological environment is prepared to recognize these biopolymers and to interact with them metabolically. 


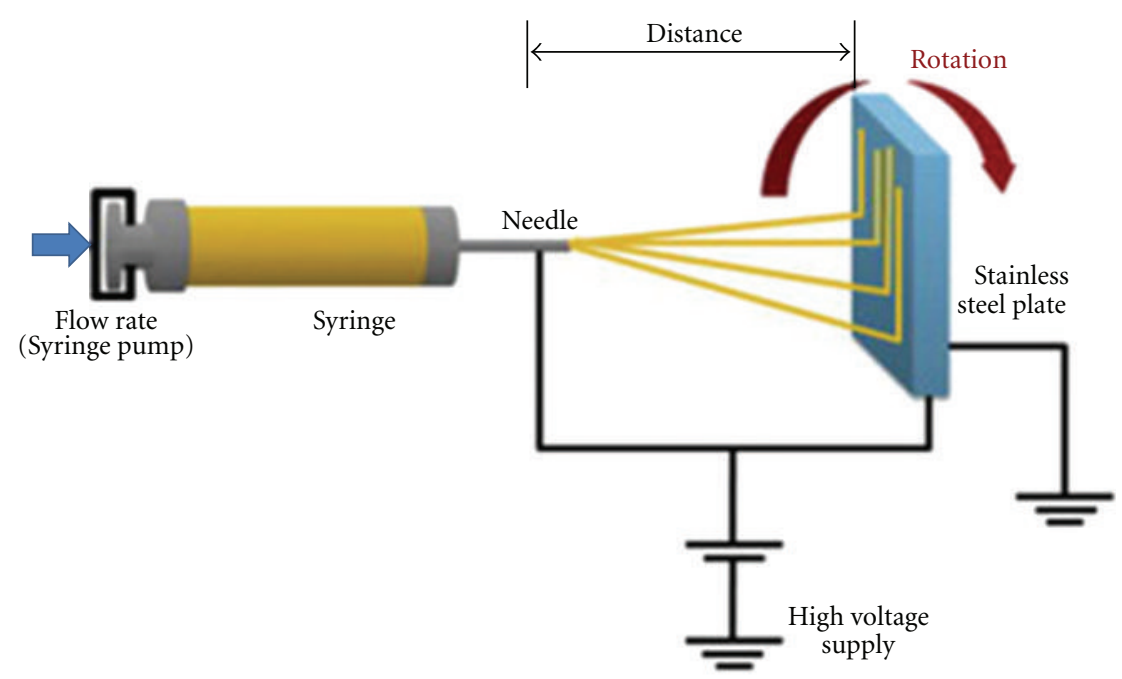

FIgURE 1: Schematic illustration of the electrospinning setup. The mandrel can be rotated at various speeds to achieve different fiber orientations. Reproduced from Biomaterials with permission from Elsevier [21].

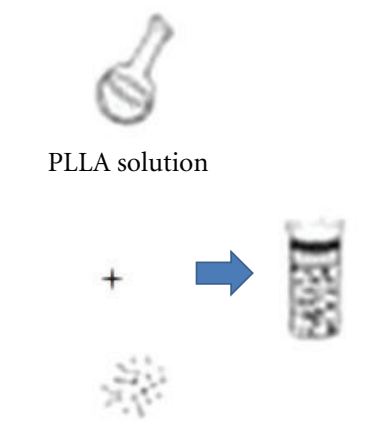

Nano-hydroxyapatite
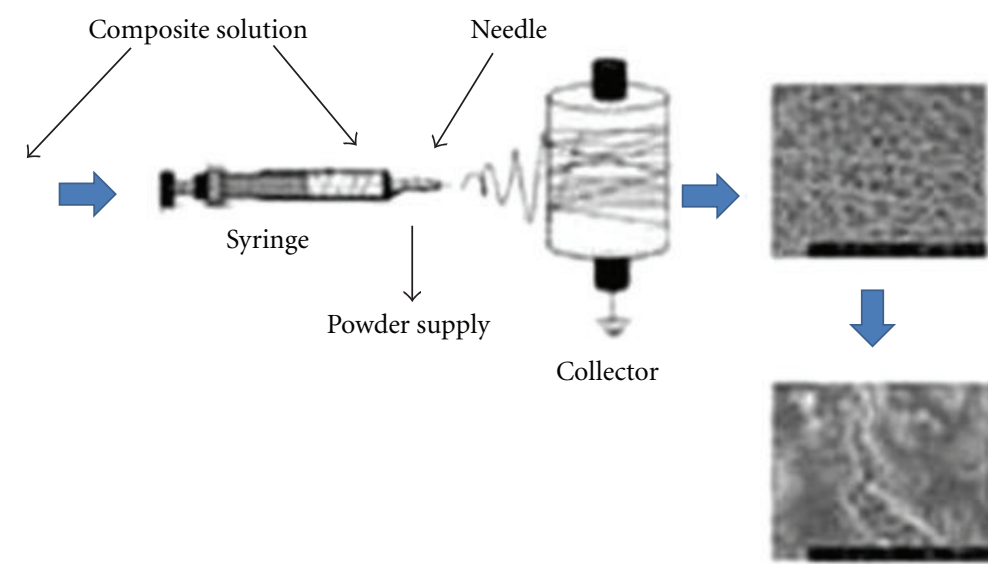

Cell culture

FIgURE 2: Schematic illustration of the preparation of the PLA/HA nanofibrous scaffolds by electrospinning technique. reproduced from Macromolecular Bioscience with permission from Wiley-VCH Verlag GmbH \& Co. [51].

Another attractive feature of natural polymers is their ability to be cleaved by naturally occurring enzymes, facilitating degradation by physiological mechanisms [13]. Synthetic biodegradable polymers are already used extensively in the biomaterials field including biodegradable aliphatic polyesters, such as poly(lactic acid) (PLA), poly(glycolic acid) (PGA), poly(caprolactone) (PCL), or poly(hydroxyl butyrate) (PHB) and its copolymers. These biodegradable materials have already been shown to have excellent biological performance both in vitro and in vivo for bone and for cartilage tissue engineering applications. Most synthetic polymers are degraded via hydrolysis. The polyester bonds of synthetic polymers are hydrolysed in nontoxic natural metabolites and are eliminated from the body by the normal physiological processes [14]. Therefore, composite materials using synthetic and natural-based polymer materials are increasingly being developed and designed to improve their biological performance $[4,6]$.

Electrospinning has been explored as an efficient process for obtaining nanofibers with diameters in the submicrometer range [15]. The interesting properties of electrospun fibers include increased surface-area-to-volume ratio as a consequence of the diameter, and the high interconnectivity and porosity of the nanofiber scaffolds at the micrometer length scale [16]. Another inherent feature of the electrospun nanofibers is their ability to mimic the extracellular matrix (ECM) of a variety of tissues, which can create a more favorable microenvironment for the cells [11]. Thus, their use in tissue/organ repair and regeneration as biocompatible and biodegradable medical implant devices 

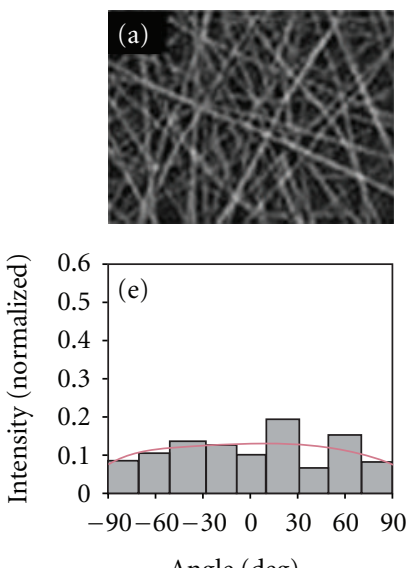

Angle (deg)
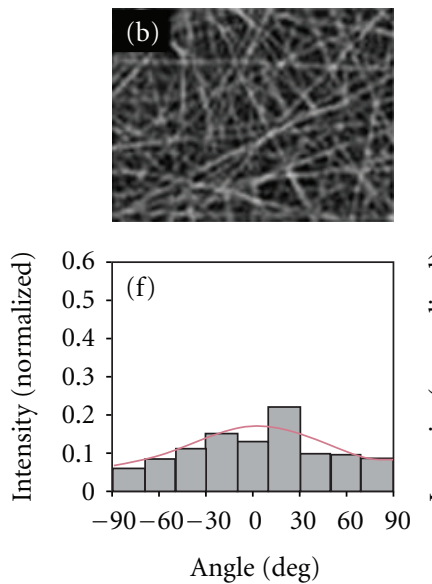
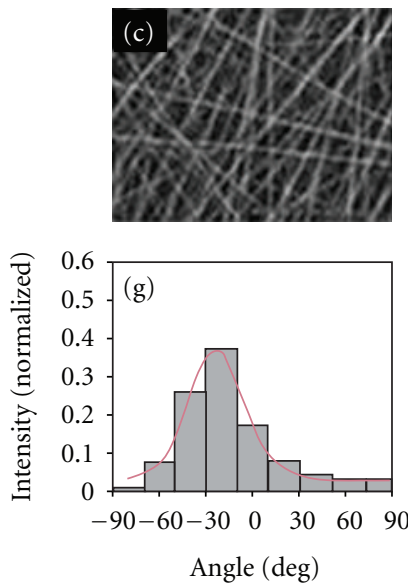
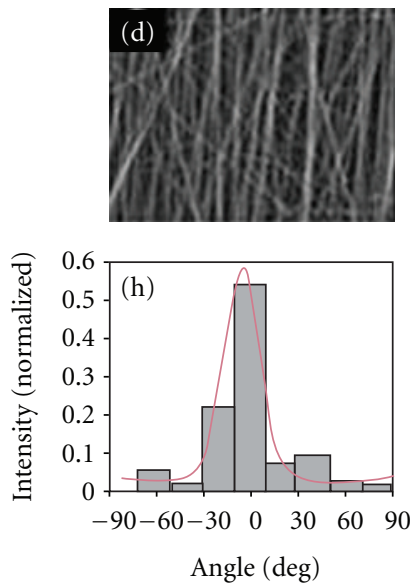

FIGURE 3: Fiber angles for the different rates of rotation: (a)-(d) SEM images of electrospun PCL/collagen nanofibers $(\times 4.0 \mathrm{k}$ magnification) and (e)-(h) normalized histograms of fiber angle, (a), (e) static, (b), (f) $800 \mathrm{rpm}$, (c), (g) $1500 \mathrm{rpm}$, and (d), (h) $2350 \mathrm{rpm}$. Reproduced from Biomaterials with permission from Elsevier [21].

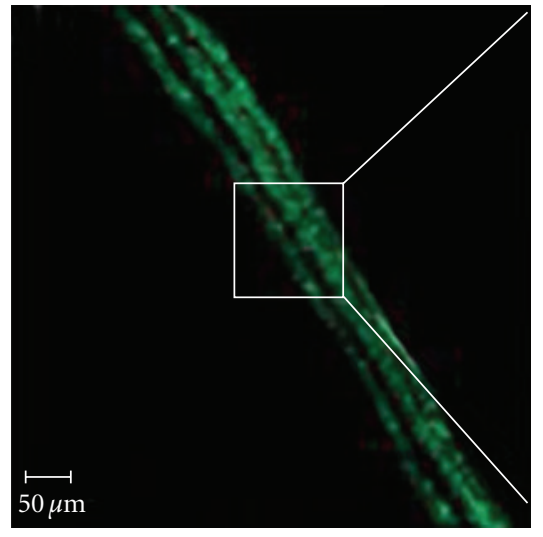

(a)

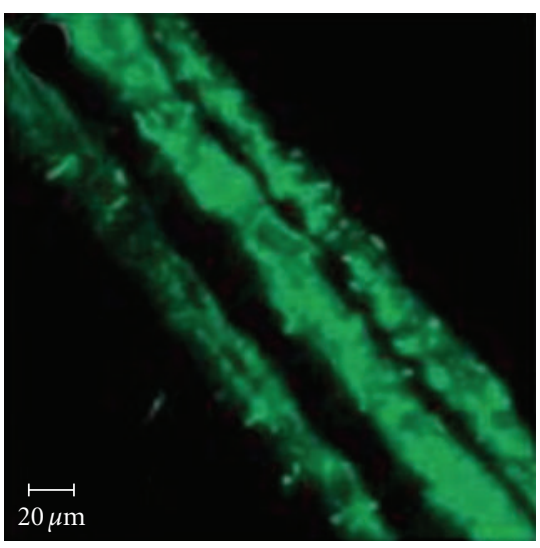

(b)

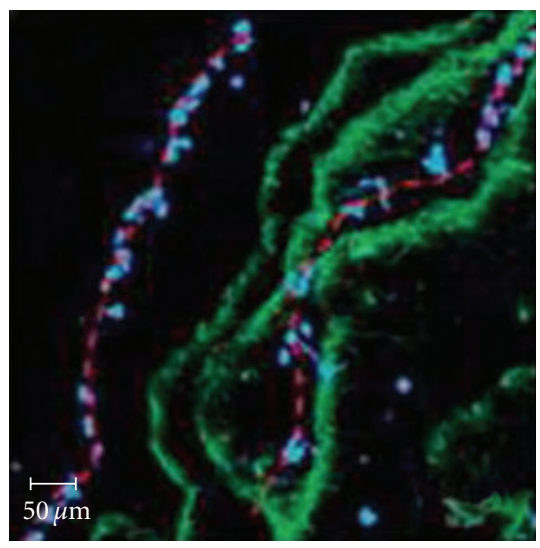

(c)

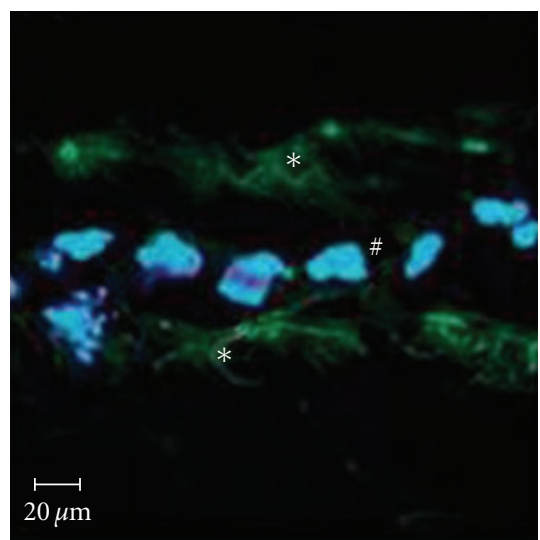

(d)

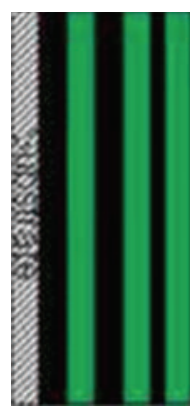

PCL/collagen

PCL/FITC-BSA

(e)

FIgURE 4: Fluorescence images of transverse sections of the nanofibrous structure. (a) and (b) Multifunctional scaffolds prepared by sequentially electrospinning of solutions as designated. (b) High magnification highlighting the clear layers. (c) Cell cultured in multifunctional scaffolds composed of PCL/collagen fibrous layer (outlined by red broken line) and PCL/BSA-FITC (green). High magnification $(\mathrm{d})$ clearly showed cells attached onto PCL/collagen layers (\#), but not onto PCL/BSA-FITC (*). Cell nuclei stained blue with DAPI. Scale bar: (a) and (c), $50 \mu \mathrm{m}$; (b), and (d), $20 \mu \mathrm{m}$. Reproduced from Journal of Experimental Nanoscience with permission from Taylor \& Francis [20]. 


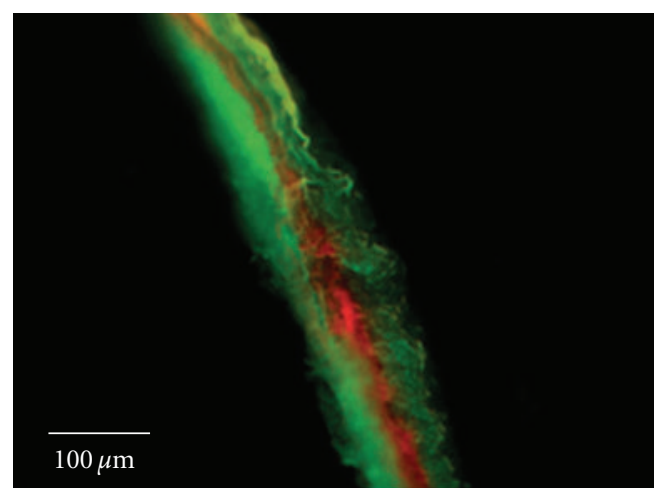

PCL/BSA-TRITC

PCL/BSA-FITC

Figure 5: Fluorescence images of transverse sections of the three-layer nanofibrous scaffold. Red: PCL/BSA-TRITC. Green: PCL/BSA-FITC. Reproduced from Journal of Experimental Nanoscience with permission from Taylor \& Francis [20].

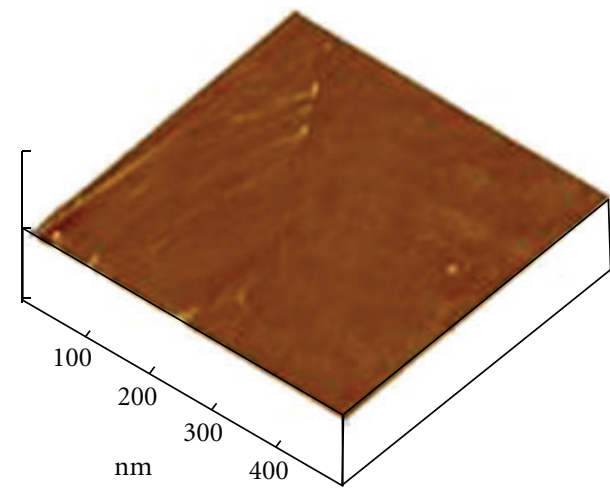

(a)

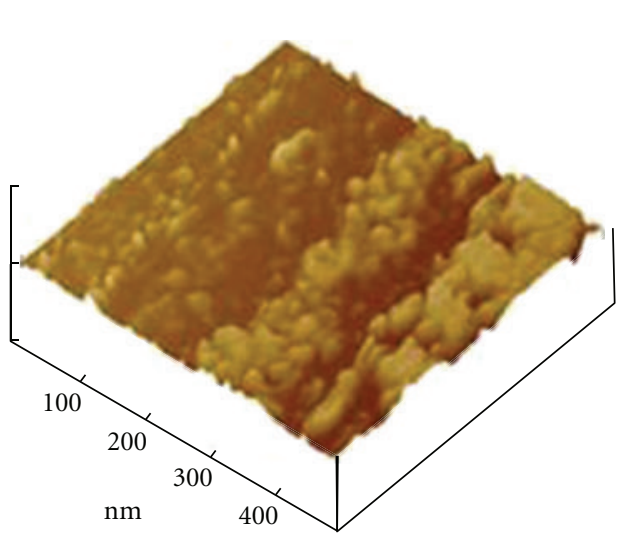

(b)

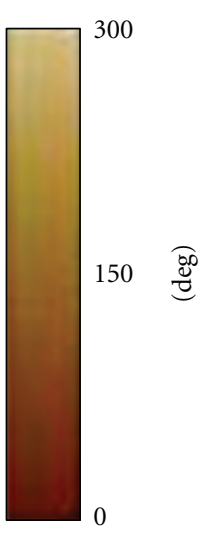

(c)
FIGURE 6: AFM images represented by phase mode: (a) PHBV fiber (b) PHBV/gelatin fiber. Reproduced from Journal of Materials Science: Materials in Medicine with permission from Springer [32]. has been suggested by many authors [17-19]. The nanoscale size of the biodegradable fibers may also offer advantages in inducing a specific kind of degradation.

Many review papers on polymer nanofibers by electrospinning and their applications in nanocomposites have been published. Huang et al. [20] summarized the processing conditions for electrsospinning of ultrafine fibers and discussed the technology limitations, research challenges, and future trends. Yoo et al. [21] reviewed that the surfaces of nanofibrous meshes can be modified by plasma treatment, wet chemical method, surface graft polymerization, and coelectrospinning in order to obtain high functionalities of electrospun nanofibers, concluded that surface-engineered nanofibrous meshes are expected to have high potentials for drug and gene delivery and TE applications. Jang et al. [22] described the electrospun materials targeted for bone regeneration, including polymers, inorganics, and their composited/hybridized compositions, and aimed at employing nanofibrous matrices for drug delivery and tissue engineering by surface functionalization, drug encapsulation and 3D scaffolding technique. Armentano et al. [23] reported on the materials, processing, experimental results, and possible interpretations of those results for polymer matrix nanocomposites. In this paper, a review has been presented on fabrication, characterization, in vitro biodegradation and cell-nanocomposite interactions of the biodegradable polyester nanocomposites by electrospinning technique for TE applications.

Recently, many researchers have focused on the developments of biodegradable polyester nanocomposites by electrospinning for TE applications. Yang et al. [24] prepared the PCL solutions $(8 \% \mathrm{w} / \mathrm{v})$ containing different amounts of bovine serum albumin (BSA) with or without collagen and electrospun into nanofibrous scaffolds. They demonstrated the feasibility of producing multiscale scaffolds with diverse functionality and tunable distribution of bioactive molecules (BSA, collagen) across the nanofibrous scaffolds. Choi et al. [25] fabricated the PCL/collagen composite nanofibrous scaffolds by electrospinning and concluded that the scaffolds are biocompatible, biodegradable, easily fabricated, and are able to support cell adhesion, proliferation, and differentiation. Yin et al. [26] proved that PLA/silk fibroin (SF)-gelatin fiber membranes, in particular, the scaffold of PLA/SFgelatin (50:50), which had both a good toughness and pliability, could provide a good environment for cell growth and proliferation of cells. Spadaccio et al. [27] demonstrated that electrospun poly (L-lactic acid)/hydroxyapatite (PLLA/HA) nanocomposites can induce differentiation of human mesenchymal stem cells (hMSCs) in chondrocytelike cells that produce proteoglycan-based matrix. Xing et al. [28] prepared the poly (3-hydroxybutyrate-co-3hydroxyvalerate)/silver (PHBV/Ag) nanocomposites and showed that the PHBV/Ag composites nanofibrous scaffolds inhibited the proliferation of bacteria, whereas the composites did not show in vitro cell cytotoxicity.

The aim of this paper is to put in evidence the evolution and potentiality of emergent biodegradable polyester nanocomposite approaches by electrospinning technique for TE applications. Therefore, this paper reviews current research 


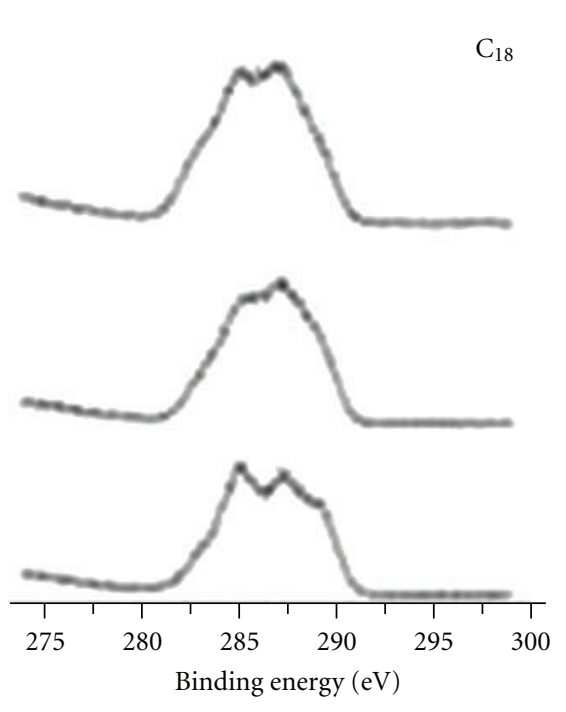

(a)

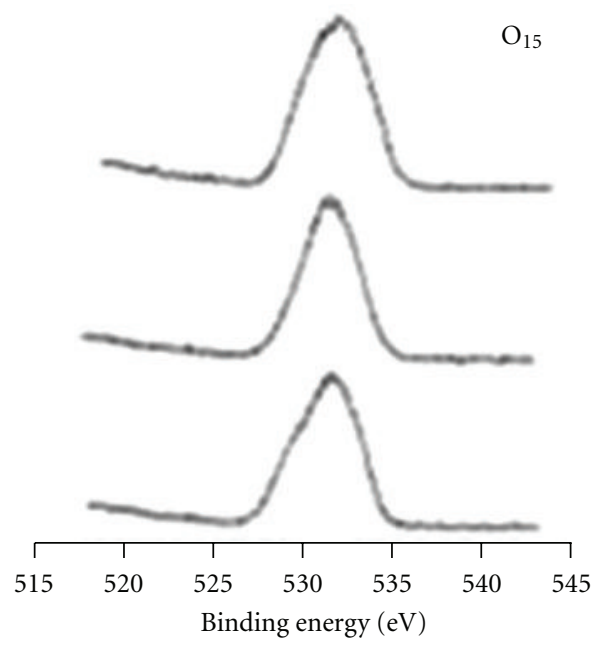

(c)

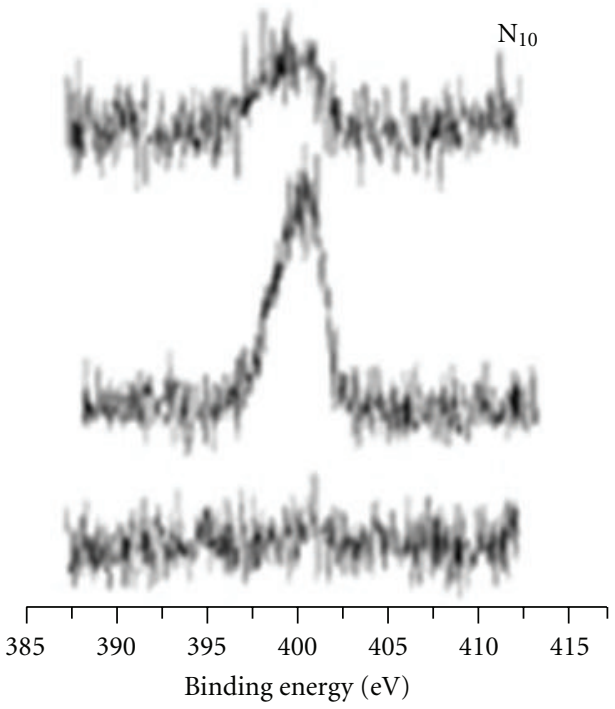

(b)

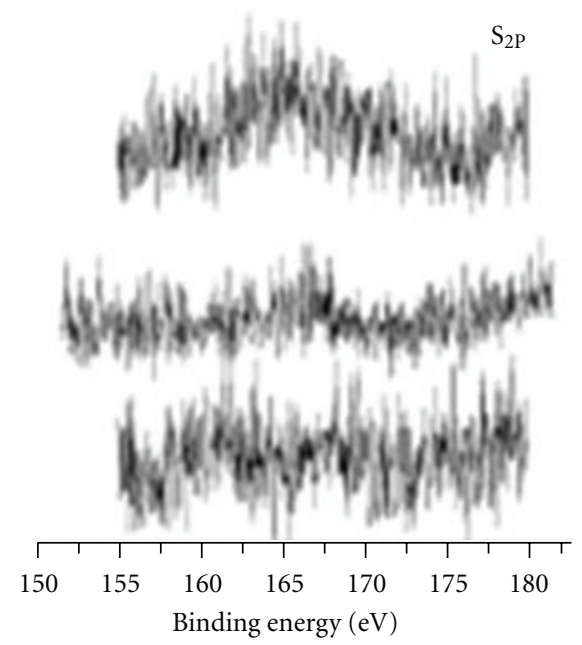

(d)

FIGURE 7: Electron spectroscopy for the chemical analysis survey scan spectra of mats (upper trace: PLA/keratin; middle trace: PLA/gelatin; lower trace: PLA). Reproduced from Polymer International with permission from John Wiley and Sons [34].

trends on relevant electrospun polyester nanocomposite materials for TE applications: biodegradable polymers, natural ECM molecules, organic/inorganic nanostructures, matrixstructure interaction, including strategies for fabrication of polyester composite nanofibrous scaffolds. The characterizations of electrospun biodegradable polyester nanocomposites are reviewed. Moreover, the in vitro degradation behaviors of nanofibrous scaffold composites for TE applications and cell-nanocomposite interactions are also discussed.

\section{Structures for Electrospun Biodegradable Polyester Nanocomposites}

In Table 1, the biodegradable polyester nanocomposites by electrospinning technique for tissue engineering were summarized.
2.1. Natural ECM Molecules. Molecules that are naturally occurring in the ECM are ideal materials for cell attachment, proliferation, and differentiation. In addition, substrate interactions between cells and ECM molecules may modulate certain cell functions. Biofunctional nanofibers can be directly fabricated by electrospinning natural ECM molecules alone or a blend of synthetic polymers and natural ECM molecules (Table 1). Nanofibrous composites generally have a benefit from improved physical properties due to polymer components and improved bioactivity due to the natural ECM components $[29,30]$.

Collagen is a natural ECM component of tissues, such as skin, bone, tendon, ligament, and other connective tissues. Therefore, it has a more native surface which favors cellular attachment as well as being chemotactic to cells when compared to synthetic polymers. It is well known that collagen plays an essential role in providing a scaffold for cellular 
TABLE 1: Summary of biodegradable polyester nanocomposites by electrospinning technique for tissue engineering.

\begin{tabular}{|c|c|c|c|c|c|}
\hline \multicolumn{2}{|c|}{ Composition } & \multirow[t]{2}{*}{ Solvent } & \multirow[t]{2}{*}{ Concentration } & \multirow[t]{2}{*}{ Perspective applications } & \multirow[t]{2}{*}{ Ref. } \\
\hline Main component & Abbreviation & & & & \\
\hline \multirow[t]{13}{*}{$\begin{array}{l}\text { Natural ECM } \\
\text { molecules }\end{array}$} & Collagen-PCL & $\begin{array}{l}\text { 1,1,1,3,3,3-hexafluoro-2- } \\
\text { propanol } \\
\text { (HFIP) }\end{array}$ & $8 \mathrm{wt} \%$, & Tissue engineering, & {$[24]$} \\
\hline & & & $5 \mathrm{wt} \%$, & Skeletal muscle defects, & {$[25]$} \\
\hline & & & $3 \mathrm{wt} \%$ & Biomedical application & {$[31]$} \\
\hline & Collagen-PHBV & HFIP & $6 \mathrm{wt} \%$ & Biological dressing, & {$[32]$} \\
\hline & & & & Tissue engineering & [33] \\
\hline & Gelatin-PCL & HFIP & $6 w t \%$ & Nerve tissue engineering & {$[34]$} \\
\hline & Gelatin-PHBV & HFIP & $6 \mathrm{wt} \%$ & Biological dressing, & {$[32]$} \\
\hline & & & & Tissue engineering & {$[35]$} \\
\hline & Gelatin-PLA & $\begin{array}{l}\text { 2,2,2-trifluoroethanol } \\
\text { (TFE) HFIP }\end{array}$ & $15 \mathrm{wt} \%$ & Tissue regeneration, & {$[36]$} \\
\hline & & & & Tissue engineering & {$[37]$} \\
\hline & Keratin-PLA & HFIP & $15 \mathrm{wt} \%$ & Tissue engineering & [37] \\
\hline & Keratin-PHBV & HFIP & $6 \mathrm{wt} \%$ & Biomedical application & [38] \\
\hline & Dextran-PLGA & DMSO/DMF $(1: 1 \mathrm{v} / \mathrm{v})$ & $300 \mathrm{mg} / \mathrm{mL}$ & Wound closure & [39] \\
\hline \multirow[t]{4}{*}{ Hydroxyapatite } & HA-PLLA & Dichloromethane & $0.2 \mathrm{mg} / \mathrm{mL}$ & Cartilage tissue & {$[27]$} \\
\hline & & & & engineering, & {$[40]$} \\
\hline & & Tetrahydrofuran & $0.05 \mathrm{~g} / \mathrm{mL}$ & $\begin{array}{l}\text { Bone tissue regeneration, } \\
\text { Tissue engineering }\end{array}$ & {$[41]$} \\
\hline & HA-PLA & TFE & $10 \mathrm{wt} \%$ & Bone tissue regeneration & {$[42]$} \\
\hline \multirow[t]{2}{*}{ Metal nanoparticles } & Ag-PHBV & TFE & $6 \mathrm{wt} \%$ & Joint arthroplasty & {$[28]$} \\
\hline & Ag-PLGA & HFIP & $4 \mathrm{wt} \%$ & Tissue engineering & {$[43]$} \\
\hline
\end{tabular}

support and thereby affecting cell attachment, migration, proliferation, differentiation, and survival. Collagen has been used in a variety of TE applications [44, 45]. Composite nanofibrous scaffolds containing collagen and biodegradable polymers such as PCL are easily fabricated by electrospinning when both materials are dissolved in the same solvent [46]. In the nanocomposites containing collagen and PCL, collagen was well dispersed as small spherical aggregates at low concentrations (10 wt\%) and much larger irregular shapes at higher concentrations (50 wt \%) [31]. Cells cultured on biodegradable nanofibers blended with collagen have shown better attachment, growth, and ECM production than nanofibers without collagen incorporation [32, 33].

Among the natural biopolymers, gelatin can be obtained by denaturing collagen and has almost an identical composition and biological properties as those of the parent collagen. Much attention has been focused on the use of gelatin as a TE material due to its low cost. Gelatin nanofiber composites could be electrospun by the combination of gelatin and other biodegradable polymers in one solution with a variety of fiber diameters. Cells attached and proliferated better on biodegradable nanofibers when they were blended with gelatin $[32,34-36]$. Increases in cell attachment and proliferation have been shown to be a function of the ratio of gelatin in the fiber blends [30]. PCL nanofibers blended with gelatin also enhanced nerve differentiation as compared to plain PCL nanofibrous scaffolds [34].
Keratin is a chief component found in hair, skin, fur, wool, horns, and feathers. Reinforced with calcium salts, it is also found in hooves, nails, claws, and beaks [47]. Keratin can be used in a variety of biomedical applications due to its biocompatibility and biodegradability. Keratin containing composite nanofibrous scaffolds can be obtained by electrospinning of keratin and other biodegradable polymers such as PLA [37] in one solution. The keratin containing biodegradable composites could increase the cell adhesion and accelerate the cell proliferation when compared to the biodegradable polymeric nanofibrous scaffolds [37, 38].

Dextran is highly soluble in an aqueous environment, but photocrosslinked methacrylated dextran nanofibers form stable hydrogels in an aqueous environment [48]. Blended PLGA/dextran nanofibers have also been fabricated and have demonstrated favorable TE properties [39].

2.2. Hydroxyapatite. Hydroxyapatite $\left(\mathrm{Ca}_{10}\left(\mathrm{PO}_{4}\right) 6(\mathrm{OH})_{2}\right)$ (HA) is the major mineral component (69\% wt.) of human hard tissues. It could be natural or synthetic, and it possesses excellent biocompatibility with bones, teeth, skin, and muscles, both in vitro and in vivo. HA promotes faster bone regeneration, and direct bonding to regenerated bones without intermediate connective tissues. HA has been developed as a bone graft substitute and it is currently used in clinical applications [49-52]. Recent research suggested that better osteoconductivity would be achieved if synthetic 

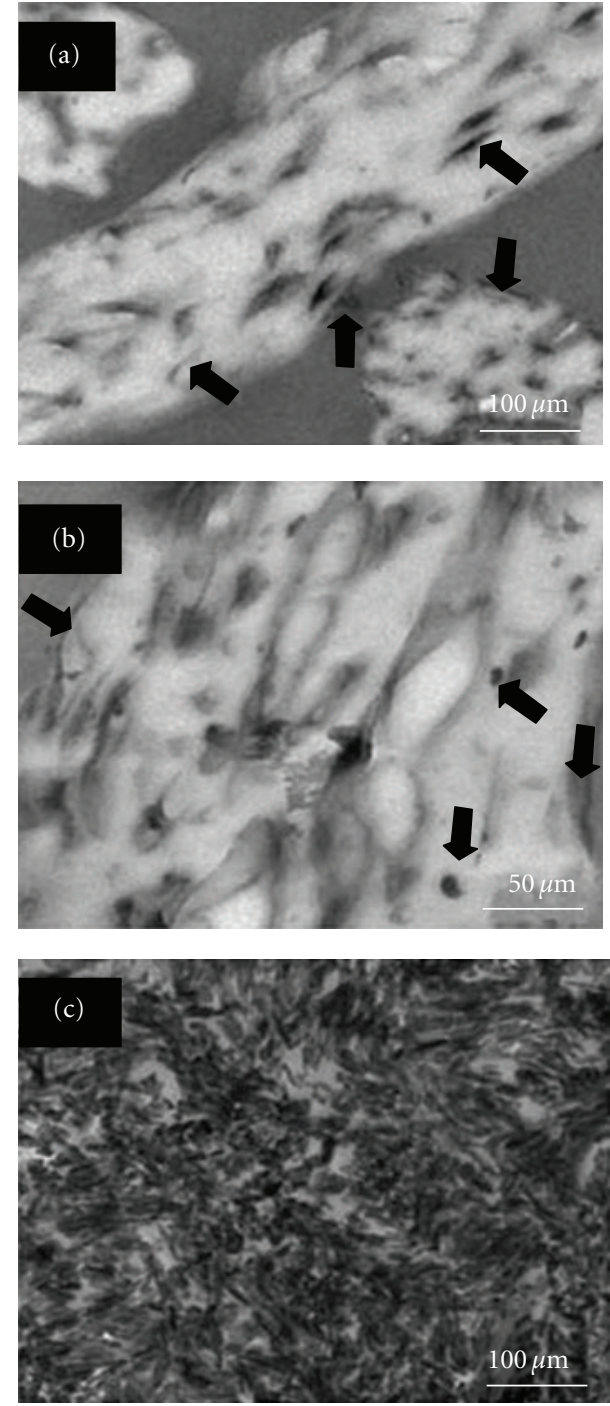

Figure 8: TEM micrographs of (a) PLA-HA1, (b) PLA-HA2, and (c) HA nanopowders. The arrows indicate the HA nanoparticles embedded within the PLA/HA composite nanofibers. Reproduced from Macromolecular bioscience with permission from Wiley-VCH Verlag GmbH \& Co. [51].

HA could resemble bone minerals in composition, size, and morphology [53]. However, due to the brittleness of the HA and the lack of interaction with the polymer, the ceramic nanoparticles may present deleterious effects on the mechanical properties, when added at high loadings.

The incorporation of $\mathrm{HA}$ in a polymeric matrix has to overcome processing and dispersion challenges since it is of a great interest to the biomedical community (Table 1). Consequently, a desirable material in TE should be a biodegradable structure that induces and promotes new formation at the required site. Sui et al. [40] fabricated PLLA/HA composite scaffolds via electrospining and concluded that the cell adhesion and growth on the PLLA/HA composite scaffolds were far better than those on the pure PLLA scaffolds. Jeong et al. [42] prepared the PLA/HA composite nanofibrous

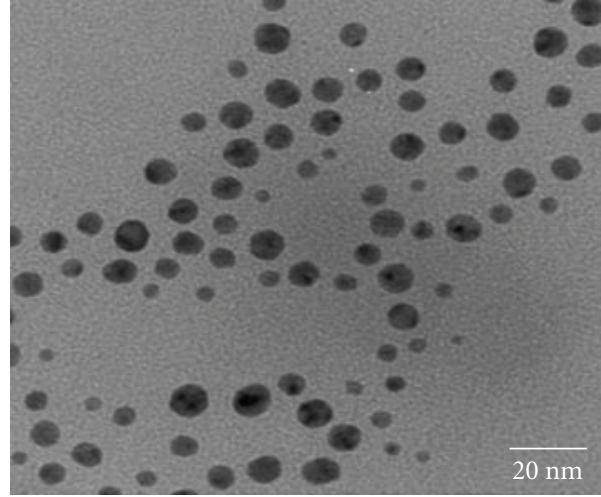

(a)

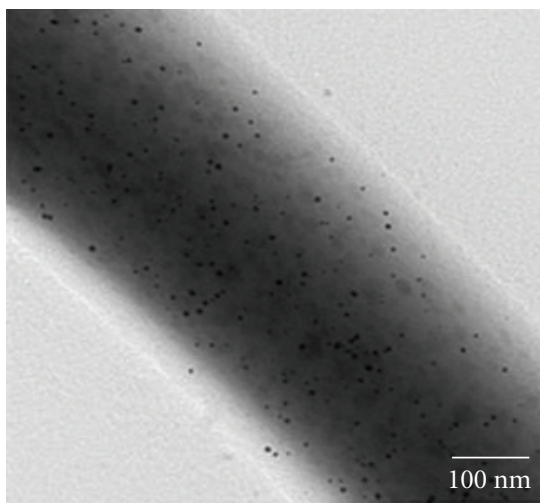

(b)

FIGURE 9: TEM images of (a) free silver nanoparticles, and (b) silver nanoparticles distributed to the PHBV nanofibrous scaffolds (PHBV/Ag 1.0). Reproduced from Biomacromolecules with permission from American Chemicial Society [24].

scaffolds and showed that MC3T3-E1 cells maintained viability and proliferated continuously for up to 21 days, suggesting that the PLA/HA composites are effective scaffolds for the growth of osteoblasts. The electrospun PLLA/HA nanocomposites [27] could be an amenable alternative for cartilage TE in combination with bone marrow hMSCs. This functionalized scaffold would provide both a surrogate of the native ECM and the correct sequence of signals to allow a harmonic ongoing lineage-specific differentiation of multipotent precursor cells.

2.3. Metal Nanoparticles. Biomedical applications of metal nanoparticles have been dominated by the use of nanobioconjugates that started in 1971 after the discovery of immunogold labeling by Faulk and Taylor [54]. Currently metal-based nanoconjugates are used in various biomedical applications such as drug delivery (vehicle for delivering drugs, proteins, peptides, DNAs, etc.), detection, diagnosis, and therapy. However biological properties of metal nanoparticles have remained largely unexplored. Therefore, in this paper the novel biological properties and applications of silver nanoparticles in the nanofibrous polyester composites are discussed (Table 1). 


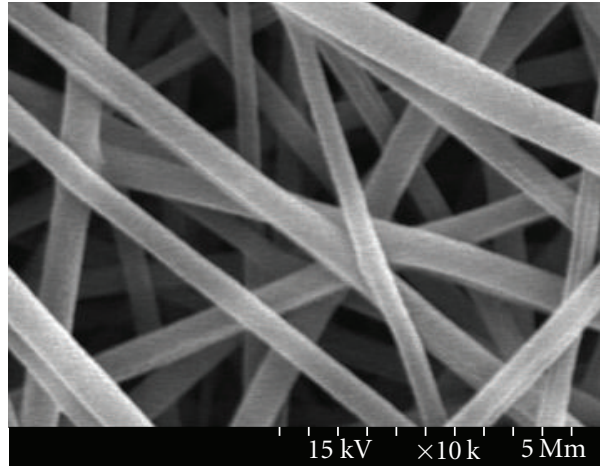

(a)

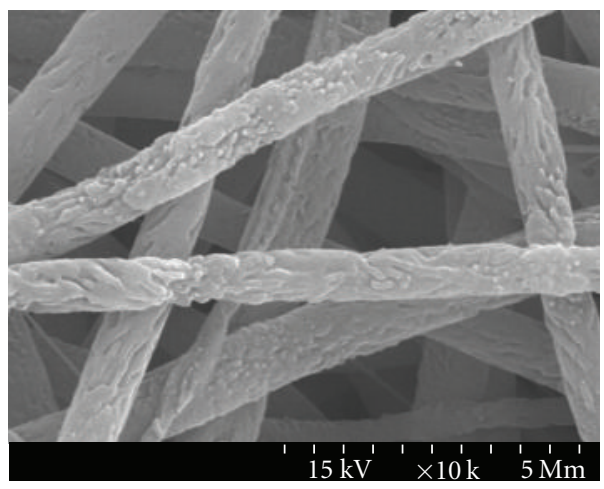

(c)

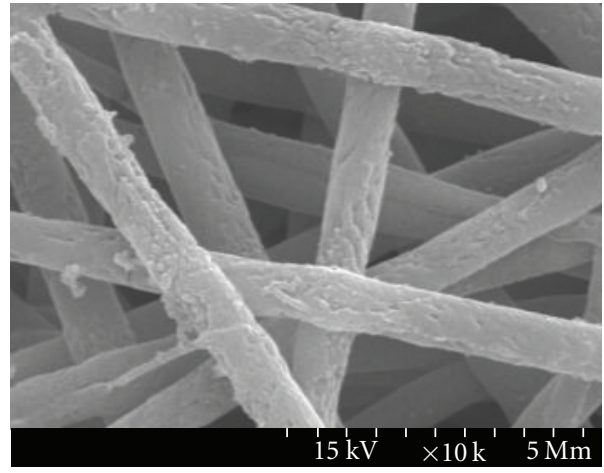

(b)

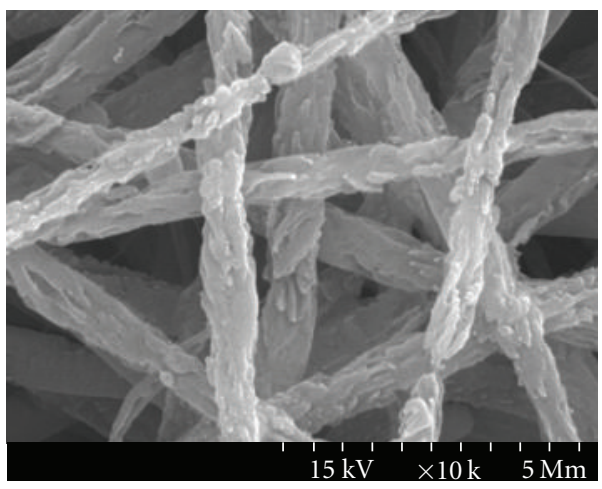

(d)

FIGURE 10: Biodegradation of PHBV/gelatin (50/50) nanofibrous scaffold by PHB depolymerase solution as a function of incubation time: (a) $0 \mathrm{~h}$, (b) $1 \mathrm{~h}$, (c) $4 \mathrm{~h}$, and (d) $6 \mathrm{~h}$. Reproduced from Journal of Materials Science: Materials in Medicine with permission from Springer [32].

Silver (Ag) nanoparticles have drawn considerable interest for their capability to release silver ions in a controlled manner which in turn leads to a powerful antibacterial activity against a large number of bacteria $[55,56]$. It has been shown that the use of nanostructured $\mathrm{Ag}$ materials enhances the inhibitory capacity. Most likely this is because the nanostructured materials have a high surface area to contact [55-57]. However, they are easily aggregated because of their high surface free energy, and they can be oxidized or contaminated in air. Embedding of $\mathrm{Ag}$ nanoparticles into biodegradable polymer matrices represents a valid solution to these stabilization problems and permits a controlled antibacterial effect [58]. Xing et al. [28] successfully prepared PHBV/Ag composite scaffolds via an electrospinning technique. They demonstrated that the PHBV composite scaffolds having silver nanoparticles with less than $1.0 \mathrm{wt} \%$ completely inhibited the proliferation of the Staphylococcus aureus (Gram-positive) and the Klebsiella pneumonia (Gram-negative) bacteria, whereas the scaffolds did not show in vitro cell cytotoxicity. The Agcontaining polyester composite nanofibrous scaffolds may have a high interest in total joint arthroplasty, particularly because of their effect against multiresistant bacteria $[28,43]$.

\section{Fabrication of Electrospun Biodegradable Polyester Nanocomposites}

The nanocomposite scaffolds composed of ECM molecules such as collagen, gelatin, keratin, and biodegradable polyesters such as PCL, PLA, and PHBV are easily fabricated by electrospinning when both materials are dissolved in the same solvent (Table 1). Choi et al. [25] fabricated the $\mathrm{PCL} /$ collagen biodegradable composite nanofibrous scaffolds using a blend of PCL and collagen with a ratio of $1: 1$ in weight. Both PCL and collagen were dissolved in 1,1,1,3,3,3hexafluoro-2-propanol (HFP) at a total concentration of $5 \%(\mathrm{wt} / \mathrm{vol})$. Then the $\mathrm{PCL} /$ collagen blend solution was electrospun using a high voltage power supply at $20 \mathrm{kV}$ potential between the solution and the grounded surface. The solution was delivered with a $5 \mathrm{~mL}$ polypropylene syringe through an 18.5 gauge blunt tip needle at a flow rate of $3.0 \mathrm{~mL} / \mathrm{h}$ using a syringe pump. Fibers were collected onto a grounded mandrel at a distance of $10 \mathrm{~cm}$ from the syringe tip. The mandrel, consisting of a stainless steel plate, was rotated at various speeds to achieve different fiber orientations (Figure 1).

HA-containing biodegradable composite nanofibrous scaffolds were obtained by the incorporation of HA nanoparticles into the biodegradable polyester nanofibers (Table 1). 


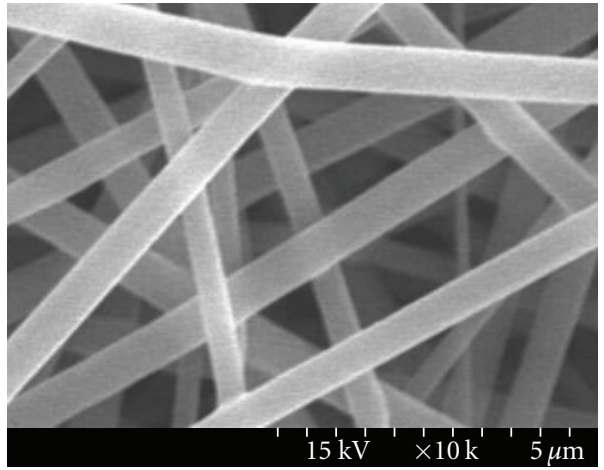

(a)

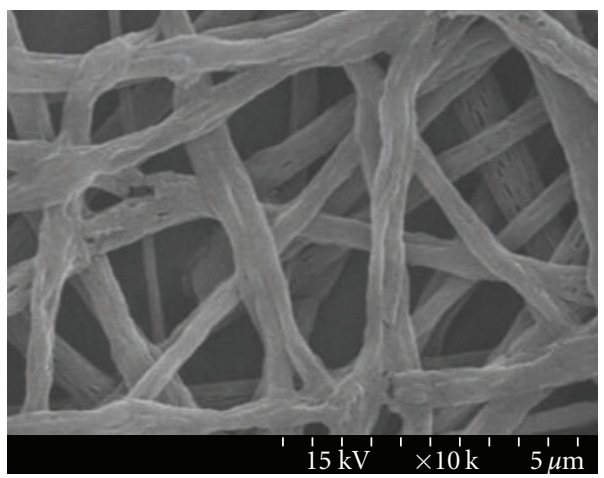

(c)

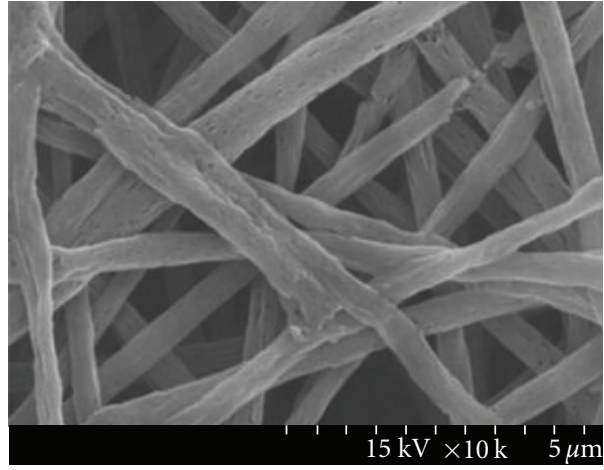

(b)

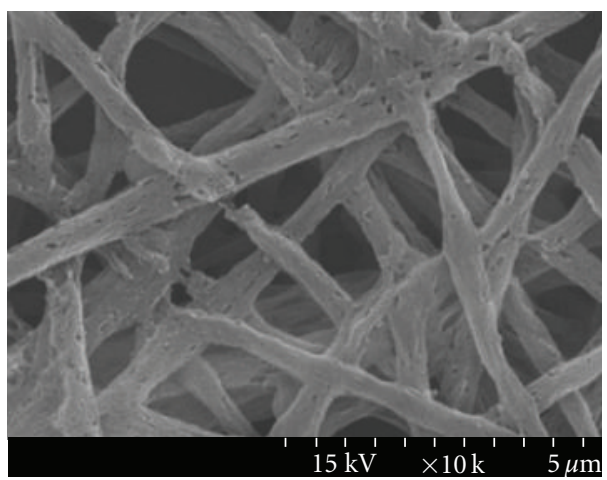

(d)

Figure 11: Biodegradation of PHBV/gelatin nanofibrous scaffold by collagenase solution as a function of incubation time: (a) $0 \mathrm{~h}$, (b) $12 \mathrm{~h}$, (c) $24 \mathrm{~h}$, and (d) $48 \mathrm{~h}$. Reproduced from Journal of Materials Science: Materials in Medicine with permission from Springer [32].

Jeong et al. [42] prepared the PLA/HA composite scaffolds directly on glass coverslips using an electrospinning technique. Briefly, PLA was dissolved in 2,2,2-trifluoroethyl alcohol (TFE, $10 \mathrm{wt} \%$ ), and HA nanoparticles were then added to the PLA solution and mixed vigorously. The resulting concentrations of HA were 5 and $20 \mathrm{wt} \%$ (in PLA). The PLA/HA mixture was loaded in a $20 \mathrm{~mL}$ glass syringe equipped with a blunt 23 gauge needle. The glass syringe was then placed in a syringe pump and the needle was connected to the positive output of a high voltage power supply. Glass coverslips were attached to aluminum foil using a doublesided tape, which wrapped around the ground collector $(9 \mathrm{~cm}$ in diameter) located at a fixed distance of $15 \mathrm{~cm}$ from the needle. The flow rate of the solution, applied voltage, and the spinning time were set to $0.85 \mathrm{~mL} / \mathrm{h}, 18-20 \mathrm{kV}$, and $8 \mathrm{~h}$, respectively (Figure 2). Following the spinning process, nanofibrous scaffolds were rinsed with distilled water three times to remove any residual chemicals, and dried at $60^{\circ} \mathrm{C}$ overnight.

Silver-containing biodegradable composite nanofibrous scaffolds were obtained by suspending the Ag nanoparticles in a biodegradable polymer solution. Xing et al. [28] prepared the PHBV/Ag composite scaffolds using electrospinning technique (Table 1). PHBV (hydroxyvaleric acid content: $5 \mathrm{wt} \%$ ) was dissolved in TFE at a concentration of $5 \mathrm{wt} \%$, and then the solution was stirred overnight at room temperature to ensure complete dissolution. Then, certain amounts of $\mathrm{Ag}$ nanoparticles (0.1 to $1 \mathrm{wt} \%$, the percentage of $\mathrm{Ag}$ nanoparticles to PHBV) were mixed with PHBV solution and stirred by magnetic stirring for $24 \mathrm{~h}$ to get the silver-containing PHBV solution. The solution was further homogenized with an ultrasonic for $2 \mathrm{~h}$. The electrospinning experiments were performed at room temperature, and the apparatus for the electrospinning was assembled based on the study carried out by Lee et al. [41].

\section{Characterization of Electrospun Biodegradable Polyester Nanocomposites}

The morphologies of the nanofibrous polymer composites could be observed by using a field emission scanning electron microscope (FE-SEM). FE-SEM images of the $\mathrm{PCL} /$ collagen composite fibers [25] showed nanoscaled fiber diameters and controlled fiber orientations (Figures 3(a)$3(\mathrm{~d})$ ). The nanofibrous composites of the PCL/collagen blend were produced from the solution having a total polymer concentration ranging from 3 to $10 \%$ (wt/vol) in HFP. The nanofibrous composites showed a linear relationship between the solution concentrations and the fiber diameters of the PCL/collagen nanofiber scaffolds with different fiber angles being produced by electrospinning at various rotation rates of 0 (static), 800, 1500, and $2350 \mathrm{rpm}$. Progressive 


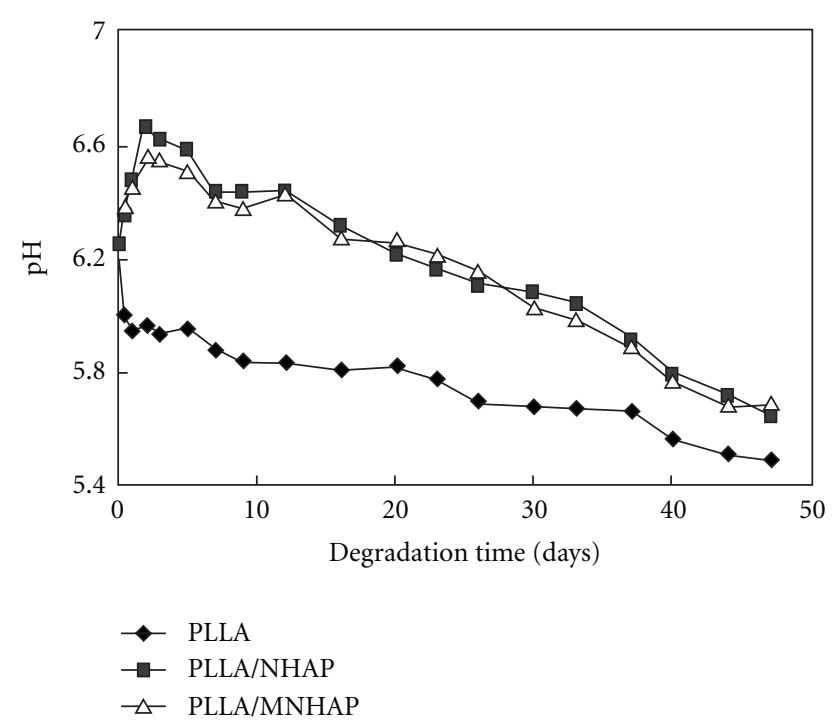

Figure 12: pH changes of PLLA, PLLA/NHAP $(80: 20$, w/w $)$ and PLLA/MNHAP $(80: 20, \mathrm{w} / \mathrm{w})$ scaffold during in vitro degradation. Reproduced from Medical Engineering \& Physics with permission from Elsevier [56].

increase in fiber orientation was observed as the rotation rate increased (Figures $3(\mathrm{e})-3(\mathrm{~h})$ ).

To test the capability of manipulating sequential deposition of different layers of fibers into a spatially graded composite nanofibrous scaffolds, a study [24] was performed using PCL only and PCL/Collagen-containing fluorescein isothiocyanate (FITC)-labeled BSA. The sequence was shown in Figure 4 and sequentially deposited multiple layers were directly collected on aluminum foil (substrate). It was found that different nanofiber materials were comparably layered as designed sequence by examining the cross-sections of collected scaffolds under a fluorescence microscope. By controlling the electrospinning time at a constant flow rate $(10 \mathrm{~mL} / \mathrm{min})$, each layer could be altered with a designated thickness, from several micro-meters to several tens of micro meters.

A more confirmative result [24] was obtained by using PCL nanofibers containing either tetramethyl rhodamine isothiocyanate (TRITC)-labelled BSA or FITC-labelled BSA for sequential deposition (Figure 5). Despite the fact that each layer was thinner on the circumferential edge of the multilayered scaffolds, the majority $(5 \mathrm{~cm}$ in diameter in the experimental setup) remained uniform and kept the deposition sequence as designed. The results indicated that the bioactive molecules can be incorporated into nanofibers and thereafter spatially arranged in a high order to form multifunctional scaffolds.

An atomic force microscope (AFM) was used to study the surface morphologies of the electrospun nanocomposites. AFM image of PHBV/gelatin composite nanofibers [35] was examined using a tapping mode and expressed as phase images. On the PHBV nanofiber surface, a relative homogeneous pattern was observed as shown in Figure 6(a). On the PHBV/gelatin composite nanofiber surface (Figure 6(b)),
TABLE 2: Chemical composition of the fiber mats calculated from ESCA survey scan spectra.

\begin{tabular}{lcccc}
\hline \multirow{2}{*}{ Mat } & \multicolumn{4}{c}{ Composition (atom \%) } \\
& $\mathrm{C}$ & $\mathrm{O}$ & $\mathrm{N}$ & $\mathrm{S}$ \\
\hline PLA & 63.1 & 36.9 & 0 & 0 \\
PLA/gelatin & 64.0 & 33.4 & 2.6 & 0 \\
PLA/keratin & 63.9 & 34.4 & 1.3 & 0.4 \\
\hline
\end{tabular}

a phase-separated structure appeared showing the distribution of gelatin on the PHBV matrix. The phase-separated structures are probably attributed to the globular structure and hydrophilicity of gelatin.

Electron spectroscopy for chemical analysis (ESCA) survey scans were used to investigate the changes in the chemical structure of the electrospun composite scaffolds. Figure 7 shows ESCA survey scan spectra of PLA/keratin, PLA/gelatin and PLA nanofibers. PLA shows two separated peaks corresponding to $\mathrm{C} 1 \mathrm{~s}$ (binding energy, $285 \mathrm{eV}$ ) and oxygen (binding energy, $532 \mathrm{eV}$ ) peaks (Figures $7(\mathrm{a})$ and $7(\mathrm{c}))$. The nitrogen (N 1s) peaks of gelatin and keratin newly appear at $400 \mathrm{eV}$ (Figure 7(b)) [37]. The other new peak at $168 \mathrm{eV}$ is attributed to sulfur (S 2p) of keratin (Figure 7(d)). Changes in the chemical structure of the nanofibrous mats were investigated using ESCA. The chemical compositions of the nanofibrous mats were calculated from a survey scan spectra and shown in Table 2. The oxygen content (36.9\%) of PLA was reduced by the incorporation of proteins. Also, nitrogen (2.6 and $1.3 \%$ ) was found on the composite mats, which is attributed to the presence of gelatin and keratin. Furthermore, a small quantity of sulfur $(0.4 \%)$ was also found on the PLA/keratin.

Transmission electron microscopy (TEM) images were used to analyze the morphologies of the nanoparticles-containing biodegradable composites. As shown in Figures 8(a) and 8(b), HA nanoparticles (approximate diameter $35 \mathrm{~nm}$ ) were uniformly and homogeneously dispersed in the organic phase of PLA nanofibers [42]. HA nanoparticles embedded within the nanofibers demonstrated spherical and elongated shapes, which are similar to those of HA only, as shown in Figure 8(c). Figure 9 shows TEM images of free silver nanoparticles and silver nanoparticles-containing PHBV nanofibers. The diameter of silver nanoparticles is in the range from 5 to $13 \mathrm{~nm}$, as shown in Figure 9(a). The spherical silver nanoparticles were randomly distributed in the PHBV nanofiber (Figure 9(b)) (PHBV/Ag 1.0) [28].

\section{In Vitro Biodegradation of Electrospun Polyester Nanocomposites}

Figure 10 illustrates the morphological changes of the nanofiber composites surfaces after incubation in phosphate buffered saline (PBS) with or without depolymerase (Pseudomonas stutzeri BM190) [35]. Before the depolymerase treatment, PHBV/gelatin composite (Figure 10(a)) exhibited a preserved nanofibrous structure. After 4-6h of incubation 


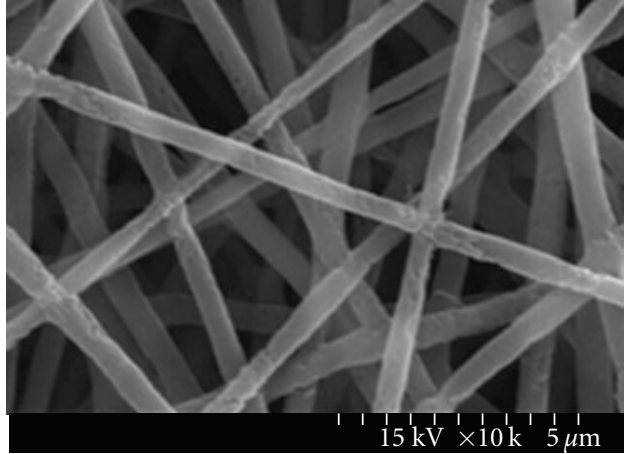

(a)

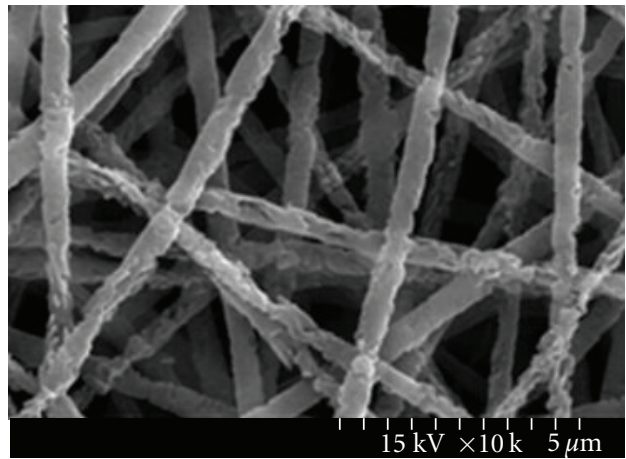

(c)

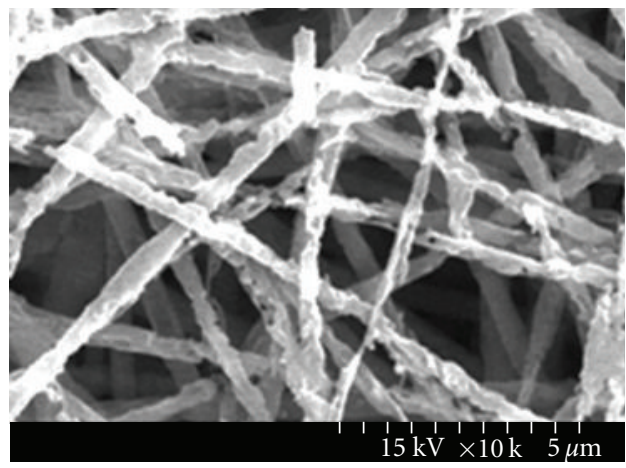

(e)

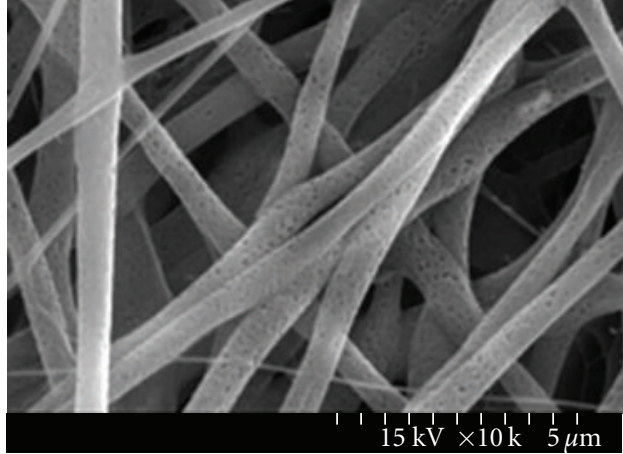

(b)

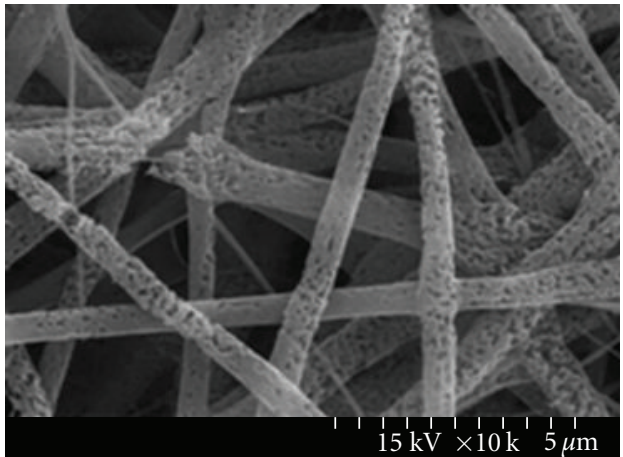

(d)

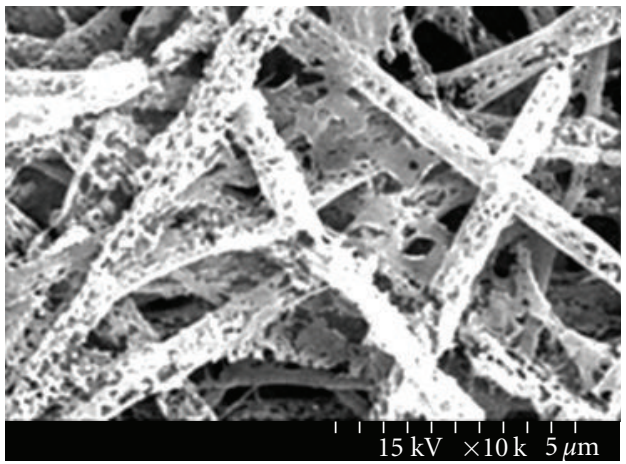

(f)

FIgure 13: SEM images of (a), (c), (e) the PHBV and (b), (d), (f) PHBV/Ag 1.0 nanofibrous scaffolds incubated in PHB depolymerase aqueous for different lengths of time. (a), (b) $1 \mathrm{~h},(\mathrm{c})$, (d) $6 \mathrm{~h}$, and (e), (f) $24 \mathrm{~h}$. Reproduced from Biomacromolecules with permission from American Chemicial Society [24].

in depolymerase aqueous solution, the PHBV nanofiber showed many morphological changes (Figures 10(c) and $10(\mathrm{~d}))$. On the other hand, after the collagenase treatment as shown in Figure 11, the PHBV/gelatin composite nanofibers broke down and partially adhered to each other after 24 and $48 \mathrm{~h}$ of incubation time.

The in vitro degradation of the PLLA/HA composite nanofibrous scaffolds is shown in Figure 12 [59]. It can be clearly seen that the $\mathrm{pH}$ of the pure PLLA degradation solution decreased remarkably from 6.25 to 5.89 in the first week, while those of the PLLA/silane-modified HA
$(80: 20, \mathrm{w} / \mathrm{w})$ and PLLA/HA $(80: 20, \mathrm{w} / \mathrm{w})$ composite scaffold increased to about 6.6 in the first 2 days, then gradually decreased after that. The increase of $\mathrm{pH}$ indicated that the degradation rate of HA was higher than that of PLLA in the first 2 days. During the testing period, it was obvious that the $\mathrm{pH}$ of the composite scaffold decreased more slowly than that of the pure PLLA scaffold. Moreover, the degradation process of PLLA became slower by the weakened acidic self-catalysis effect. Therefore, the $\mathrm{pH}$ of the PLLA/HA composite nanofibrous scaffold degradation curves declined more slowly than that of the pure PLLA 

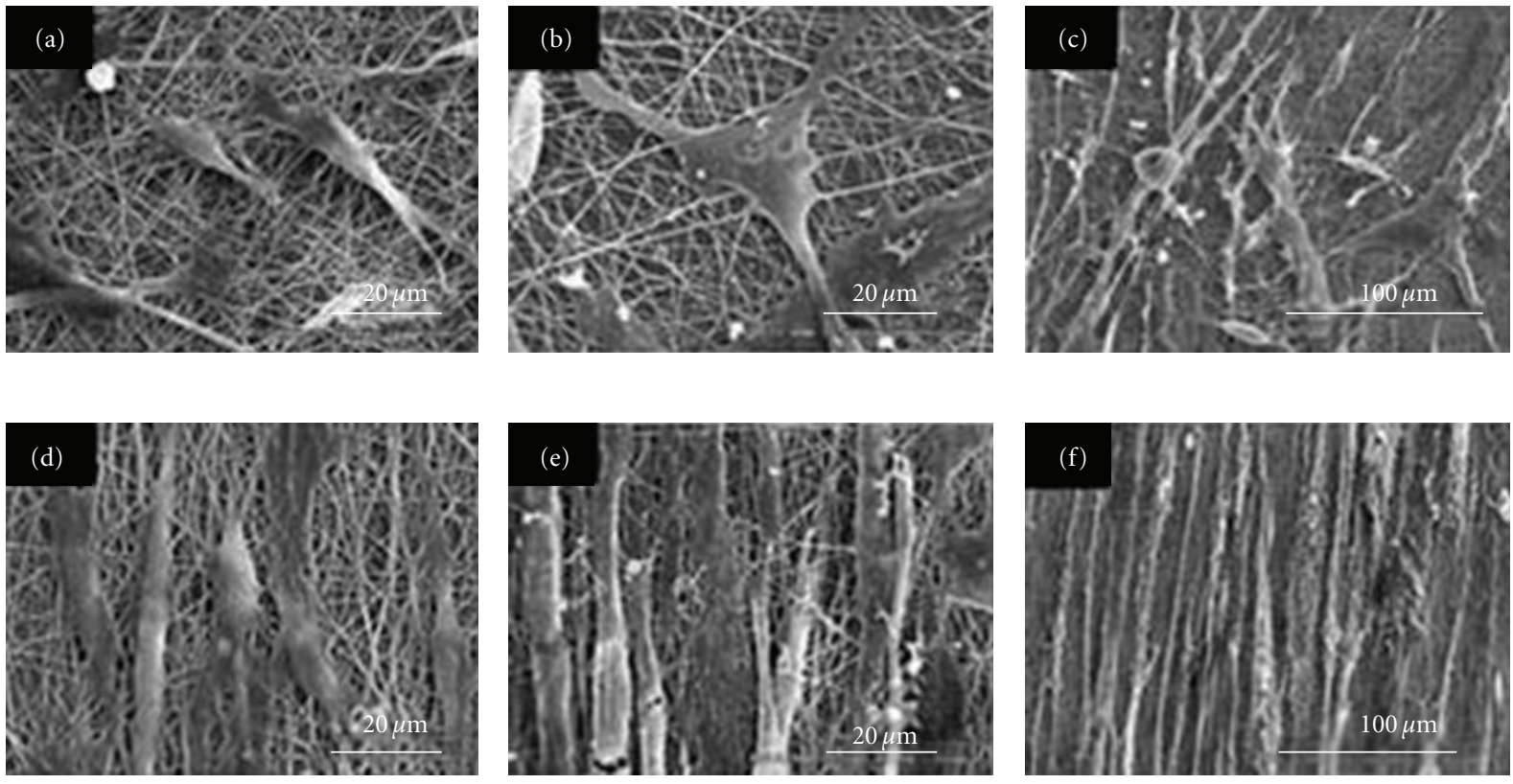

FIGURE 14: SEM images of hSkMCs on the electrospun PCL/collagen nanofiber meshes: (a)-(c) randomly oriented and (d)-(f) aligned electrospun meshes, (a), (d) 1 day and (b), (e) 3 days after cell seeding and (c), (f) 7 days after cell differentiation. Reproduced from Biomaterials with permission from Elsevier [21].

scaffold. The improved acidity atmosphere reduced the risk of indolent inflammatory reaction during the cultivation of the cell and tissue.

Figure 13 illustrates the morphological changes of the composite nanofibrous scaffold after incubation in a PBS containing PHB depolymerase for different times [28]. After $1 \mathrm{~h}$ of incubation, surface erosion appeared along the fiber axis of (a) the PHBV fibrous scaffold, whereas pores formed on the surface of (b) the PHBA/Ag 1.0 composite scaffold. Erosion of both the PHBV and the PHBV/Ag 1.0 composite scaffold increased with an increase in incubation time. However, the erosion rate of the PHBV/Ag 1.0 was faster than that of the PHBV control. It is considered that the rapid erosion of the PHBV/Ag 1.0 is due to the release of silver nanoparticles from the surface and then the subsequent biodegradation by PHB depolymerase.

\section{Cell-Nanocomposites Interactions}

In order to examine the effect of bioactive molecules incorporated into the scaffolds on cell adhesion, human dermal fibroblasts were seeded and cultured for $24 \mathrm{~h}$ on composite scaffolds composed of collagen-containing PCL fibers and PCL fibers [24]. Examination of the cross-sections of cultured constructs showed that human dermal fibroblasts had a preferential attachment to collagen-containing nanofibers, as illustrated in Figure 4 (bottom). The selective attachment of the dermal fibroblasts onto the PCL/Collagen nanofibers instead of the PCL nanofibers further demonstrated the advantage of collagen as it can promote the cell-nanofibers interaction.
SEM images taken at 1 and 3 days in the growth medium showed the presence of human skeletal muscle cells (hSkMCs) on the electrospun PCL/collagen composite nanofiber scaffolds [25] and the formation of myotubes at 7 days in the differentiation medium (Figure 14). The cells were aligned on the unidirectional oriented nanofibers after cell seeding. In contrast, the randomly oriented nanofiber scaffolds induced an irregular cellular orientation. The hSkMCs formed myotubes on the electropsun nanofibers at 7 days after cell differentiation. The myotubes formed on the oriented nanofiber scaffolds showed unidirectionally organized myotubes that are consistently aligned along the longitudinal axis of nanofibers, which is in contrast to the randomly oriented nanofiber scaffolds (Figures 14(c) and $14(\mathrm{f}))$.

Phenotypic expression of desmin, myosin heavy chain (MHC), and sarcomeric actin was confirmed on the aligned and randomly oriented nanofiber scaffolds (Figure 15) [25]. The hSkMCs were grown on the PCL/collagen composite nanofiber scaffolds in the growth medium for up to 3 days followed by incubation in the differentiation medium for up to 7 days which induced the formation of myotubes. Both the aligned and randomly oriented nanofiber scaffolds showed the maintenance of phenotypic expression of the skeletal muscle cells. In addition, the cells and myotubes were oriented along the longitudinal axis of the nanofiber direction (Figures 15(e)-15(g)). In contrast, the myotubes on the randomly oriented nanofiber scaffolds were mostly scattered in all directions (Figures 15(a)-15(c)). Confocal microscopic images confirmed that fiber orientation influenced the morphology and cytoskeletal of the hSkMCs on the nanofiber scaffolds (Figures 15(d) and 15(h)). Confocal microscopy 

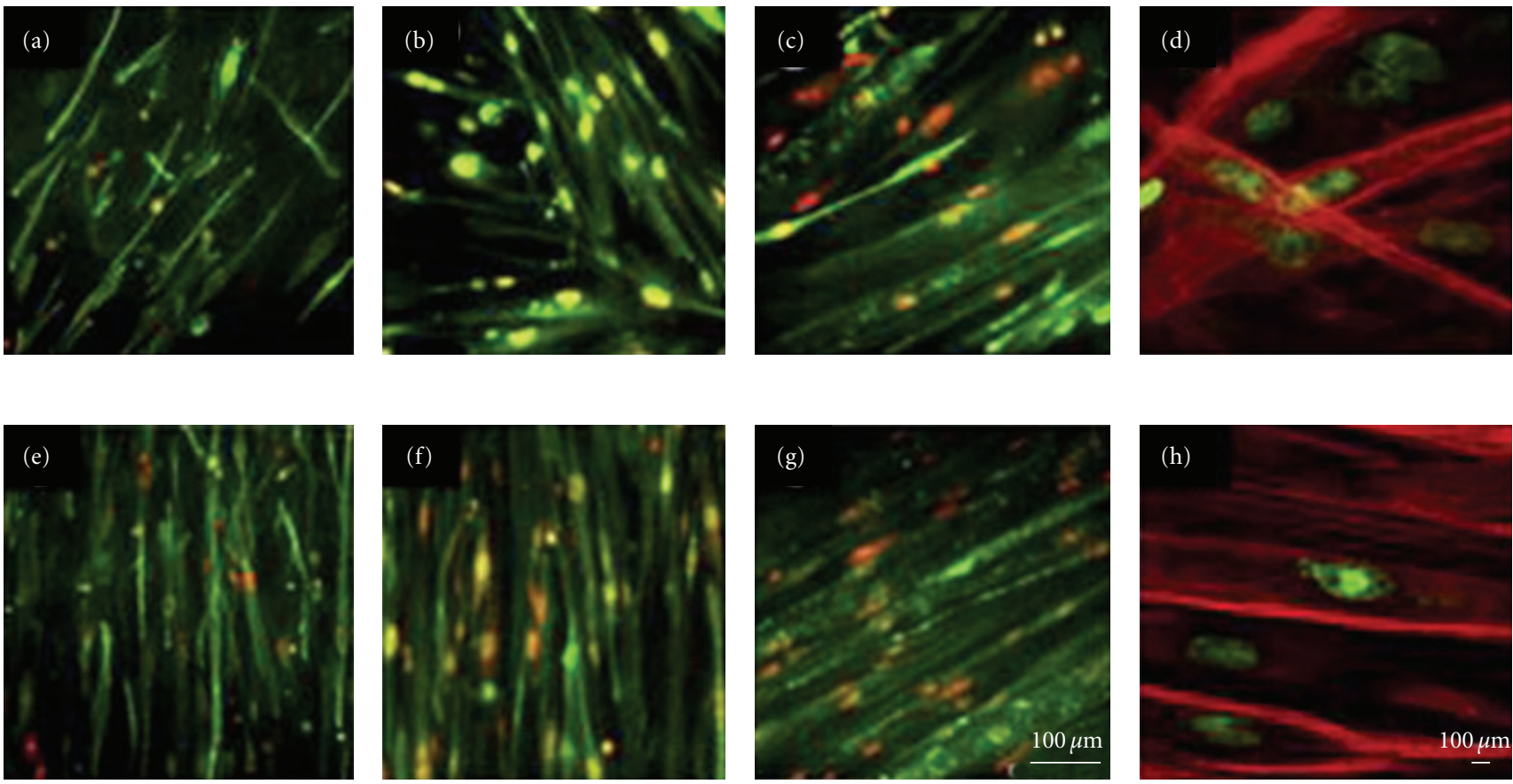

FIGURE 15: Immunofluorescent staining images of hSkMCs on the electrospun PCL/collagen nanofiber meshes: (a)-(c) randomly oriented and (e)-(g) aligned electrospun meshes; (a), (e) desmin-positive expression at 3 days after cell seeding, (b), (f) MHC-positive expression at 7 days after cell differentiation, and (c), (g) sarcomeric actin-positive expression at 7 days after cell differentiation. Laser confocal microscopy images of F-actin staining in hSkMCs seeded on the electrospun PCL/collagen nanofiber meshes ( $\times 600$ magnification): (d) randomly oriented and (h) aligned electrospun meshes. Reproduced from Biomaterials with permission from Elsevier [21].

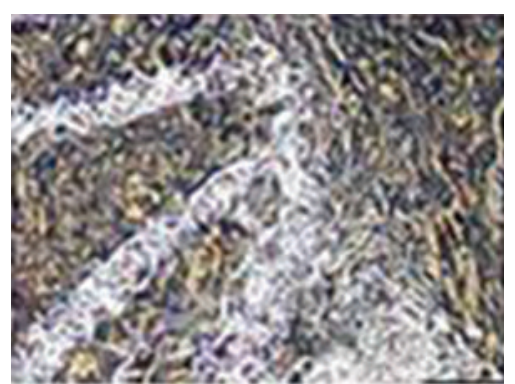

(a)

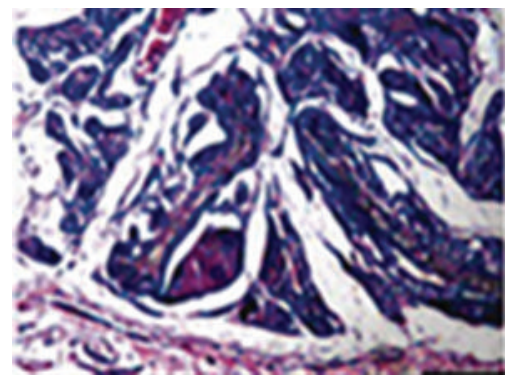

(d)

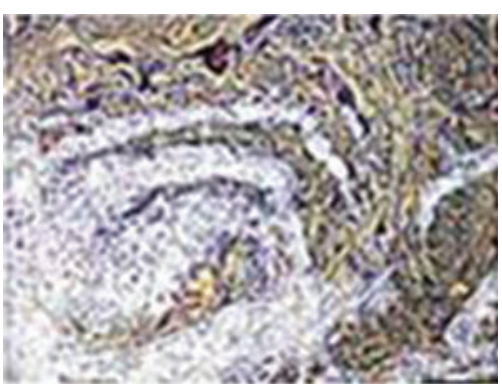

(b)

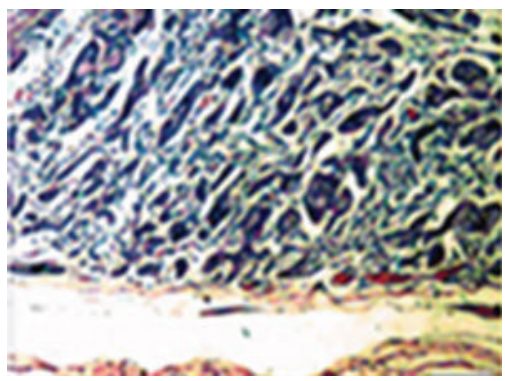

(e)

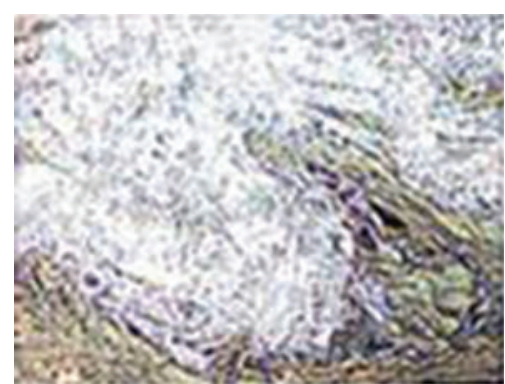

(c)

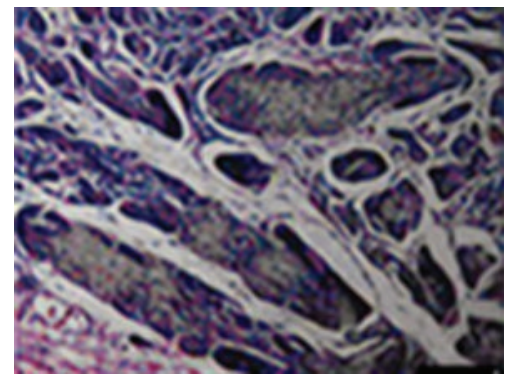

(f)

FIgURE 16: Representative photomicrographs of subcutaneous implants; PLA/SF (a), PLA/SF-gelatin (70:30) (b), and PLA/SF-gelatin $(50: 50)$ (c) at 1 month; PLA/SF (d), PLA/SF-gelatin $(70: 30)$ (e), and PLA/SF-gelatin $(50: 50)$ (f) at 3 months. Reproduced from Journal of Biomedical Materials Research with permission from John Wiley and Sons [22]. 
PLA
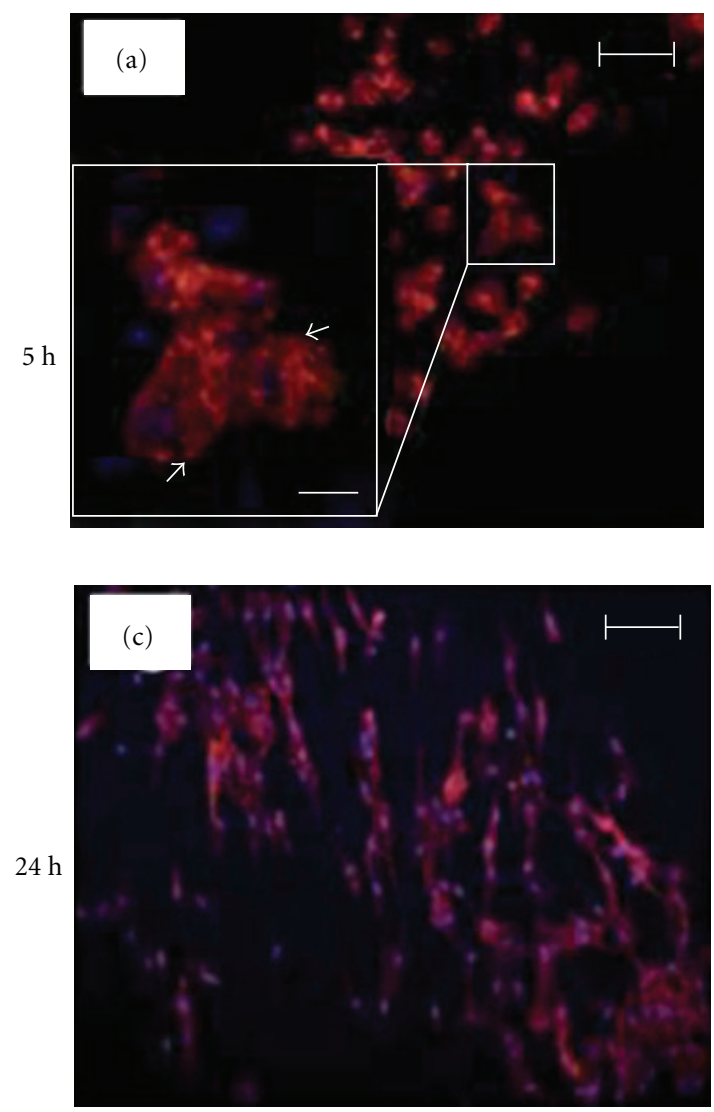

PLA-HA1
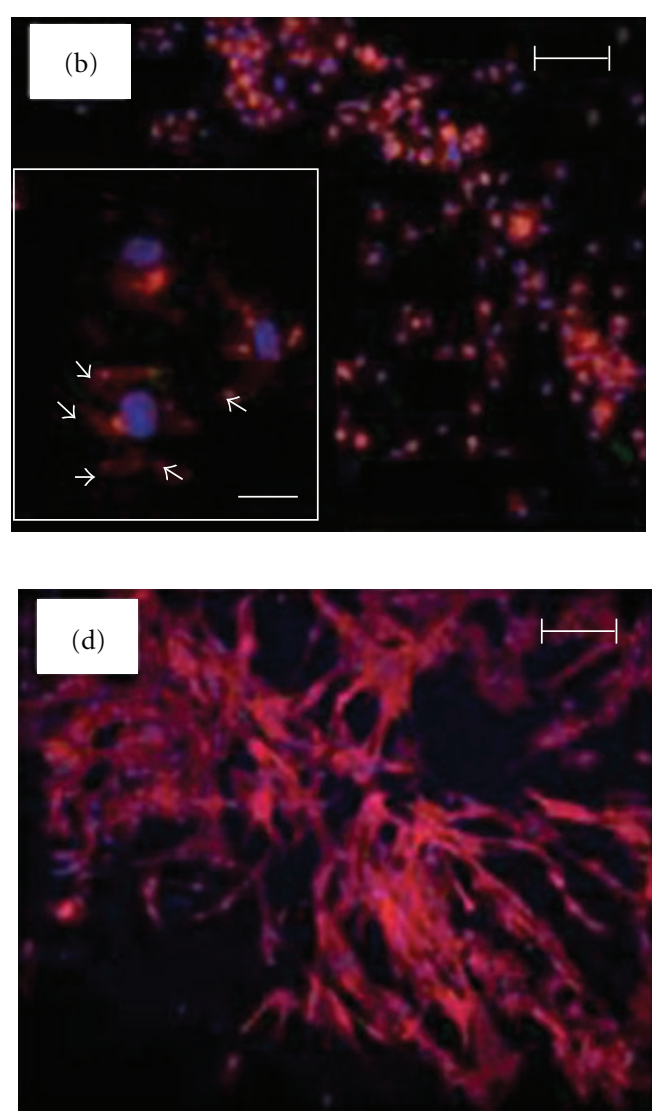

FIGURE 17: Immunofluorescence micrographs of MC3T3-E1 cells cultured on PLA (a) and (b) and PLA-HA1 (c) and (d) nanofibers for 5 and $24 \mathrm{~h}$. Scale bars in insets of (a) and (c) represent $25 \mathrm{~mm}$. F-actin stress fibers were stained with rhodamine-phalloidin. Reproduced from Macromolecular bioscience with permission from Wiley-VCH Verlag GmbH \& Co. [51].

images of the fluorescent stained F-actin on cell adhesion, proliferation, and differentiation demonstrated that the actin assembly appeared disordered on the randomly oriented nanofiber structure, whereas on the aligned nanofiber structures, the F-actin was oriented along the nanofiber direction in an organized fashion. The myotubes formed on the randomly oriented nanofiber scaffolds showed partial alignment locally and did not show a uniform cellular organization. In contrast, myotubes on the aligned nanofiber scaffolds organized within close proximity to the direction of the nanofiber direction and formed uniformly aligned myotubes.

After implantation of 1 month, Figure 16 showed that the PLA/SF-gelatin composite nanofibrous scaffolds were surrounded by the new tissue, and fewer macrophages, neutrophils, and lymphocytes were found, indicating that all three scaffold types have less inflammation and no significant rejection [26]. Furthermore, 3 months later, as shown in Figure 4, the scaffolds could guide the formation of connective vascular network tissue. Also, the shape of the implants became smaller, suggesting that PLA/SFgelatin had good biocompatibility and biodegradation in vivo.

Cell adhesion to the PLA/HA composite nanofibrous scaffolds [42] was evaluated using MC3T3 E1 pre-osteoblast cells that have been extensively characterized for their osteogenic differentiation potential [60-62]. The cytoskeletal organization of the cells attached on the nanofibers by fluorescently staining actin filaments of the adherent cells after up to $24 \mathrm{~h}$ of in vitro culture were first examined. At $5 \mathrm{~h}$ after cell seeding, preosteoblasts on the nanofiber scaffolds displayed a different degree of immature cytoskeletal structure as shown in Figures 17(a) and 17(c). The cells on the PLA/HA composite nanofibers formed an early stage of filopodial extension at the ends of intracellular actin stress fibers. On the other hand, the cells on the PLA nanofibers maintained spherical morphology and showed an accumulation of actin filaments only inside the cytoplasm, suggesting no indication of the extension of filopodia. After $24 \mathrm{~h}$, the cells on all nanofibers displayed a spindleshaped elongated morphology and extensive formation of actin stress fibers. Notably, they observed an interesting morphology of the pre-osteoblasts cultured on the PLA nanofiber featuring isotropic patterned elongation. On the other hand, the cells on the PLA/HA nanofiber showed anisotropic aggregation of a number of highly spread pre-osteoblasts with morphology that looked similar to viable osteoblasts. Taken together, despite varied cytoskeletal organization, the incorporation of HA with PLA did not 


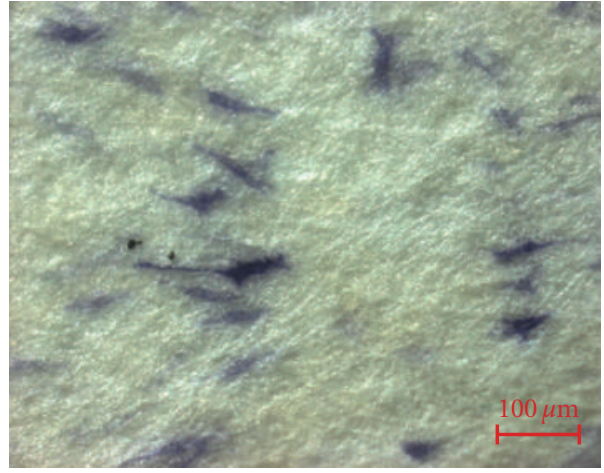

(a)

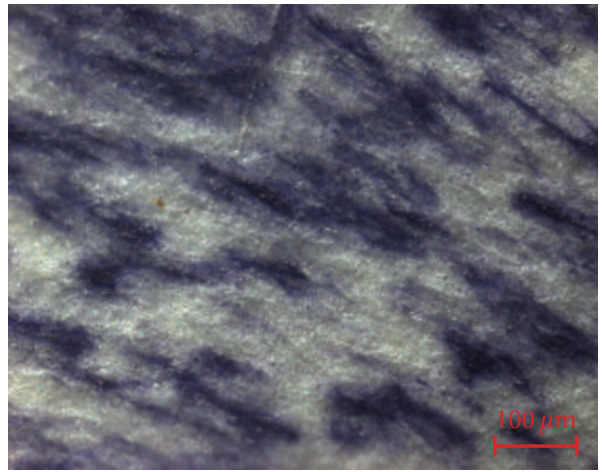

(c)

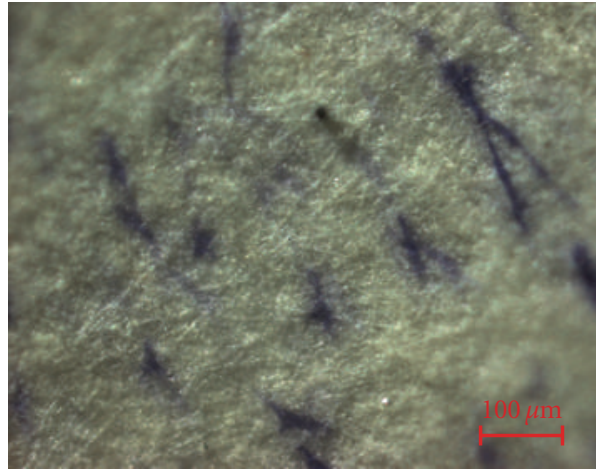

(b)

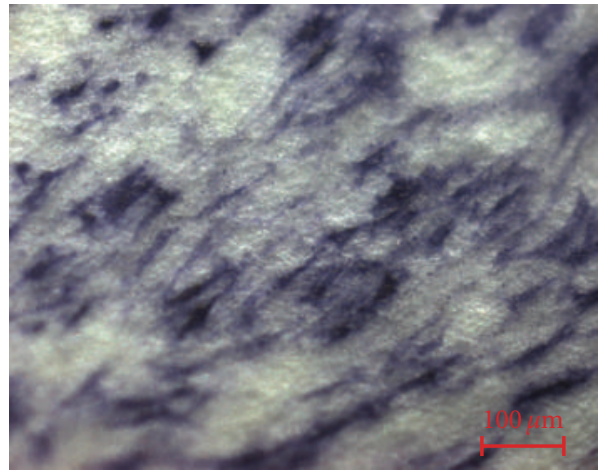

(d)

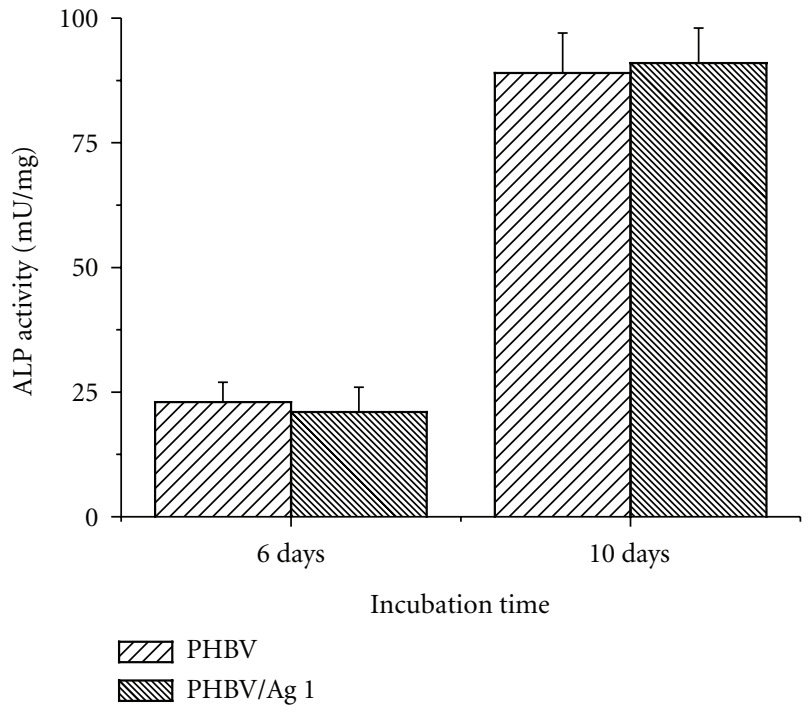

(e)

Figure 18: Alkaline phosphatase-(ALP-) stained (a) PHBV, (b) PHBV/Ag 1.0 nanofibrous scaffolds after 6 days of incubation of MC3T3-E1 osteoblasts, and (c) PHBV, (d) PHBV/Ag 1.0 nanofibrous scaffolds after 10 days incubation of MC3T3-E1 osteoblasts, and (e) ALP expression of MC3T3-E1 osteoblasts on the nanofibrous scaffolds. Reproduced from Biomacromolecules with permission from American Chemicial Society [24].

seem to compromise cell viability. The slight difference in morphologies of adherent osteoblasts may be attributed to the different degree of pore distribution or to the chemical composition of underlying scaffolds or to both factors. Specifically, previous investigations have highlighted that cytoskeletal organization and cell shape are regulated by the nanoscaled architecture of a scaffold [63, 64]. Cells can form a hierarchical cytoskeletal network by adaptation of the structure of underlying nanofiber that provides a different level of void pore space, and fiber diameters. 
Because embedding HA nanoparticles into PLA alters the chemical composition as well as the size and distribution of the fibers, further study may be necessary to investigate the effect of these individual contributions on cellular responses.

Alkaline phosphatase (ALP) activity was determined to be an indicator of osteoblastic differentiation of MC3T3-E1 cultured on PHBV and PHBV/Ag 1.0 nanofibrous scaffolds [65]. As shown in Figure 18, the ALP activities of the cells on the PHBV and PHBV 1.0 nanofibrous scaffold increased with the increase of incubation time. The degree of ALP activity expressed by the PHBV scaffold was not significantly different from that of the PHBV/Ag 1.0 for 10 days (Figure 18(e)). Haimi et al. [66] fabricated three types of bioactive glass scaffolds (nontreated, thick, and thin Ca-P treated) and reported that the ALP activity of the cells cultured for 1 week on nontreated bioactive glass scaffolds was significantly higher than that of those cultured on both thin and thick Ca-P-treated scaffolds. However, these differences equalized between the three scaffolds by the 2-week time point. Therefore, they concluded that the osteogenic differentiation appears to be delayed on the Ca-P surface-treated scaffolds. Ge et al. [67] prepared the 3D poly-(lactic-co-glycolic acid) (PLGA) scaffolds and reported that the ALP activity expressed by the osteoblasts cultured on the PLGA scaffolds was almost the same as that on the open-cell polylactic acid (OPLA) and collagen scaffolds (Becton-Dickinson, Franklin Lakes, NJ). They concluded that the PLGA scaffold can support the proliferation of osteoblasts as well as the expression of genes, which is important for osteogenesis such as ALP, osteocalcin, collagen I, and osteopontin. The PHBV is a natural polyester polymerized by bacteria. The PHBV has a biological origin and environmentally more acceptable. In their study, it is considered that both the PHBV and the silver-containing PHBV nanofibrous scaffolds can support the expression of genes which is important for osteogenesis (ALP activity).

\section{Conclusions}

Novel generations of biodegradable nanocomposites are expected to be biofunctional, intelligent, and active components. Biopolymer matrix composites have the advantage of being very versatile, allowing for the tailoring of their final properties. Biodegradable polyester nanocomposites can be designed and produced with the electrospinning technique, using a wide range of biopolymeric matrices, reinforcements and processing routes. As a result, much of the work is still ongoing, and there is yet to be a definite conclusion on the effect of nano-sized inclusions on biodegradable polymer systems. In this paper, a review has been presented on the materials, processing, experimental results, and possible interpretations of those results for biodegradable polyester nanocomposites by an electrospinning technique. The mentioned studies suggest that the combination of biodegradable polymer and nature ECM molecules or nanostructures opens new perspective in the nanodevices for $\mathrm{TE}$ applications.

\section{Acknowledgments}

This research was supported by research Grants from the Biotechnology Development Project (2009-0090907) and by Grant 2010-0011125 from the Ministry of Education, Science, and Technology of Korea.

\section{References}

[1] R. Langer and J. P. Vacanti, “Tissue engineering," Science, vol. 260, no. 5110, pp. 920-926, 1993.

[2] R. Shalak and C. F. Fox, "Preface," in Tissue Engineering, R. Shalak and C. F. Fox, Eds., p. 26, Alan R. Liss, New York, NY, USA, 1988.

[3] J. Jagur-Grodzinski, "Polymers for tissue engineering, medical devices, and regenerative medicine. Concise general review of recent studies," Polymers for Advanced Technologies, vol. 17, no. 6, pp. 395-418, 2006.

[4] V. M. Correlo, L. F. Boesel, M. Bhattacharya, J. F. Mano, N. M. Neves, and R. L. Reis, "Properties of melt processed chitosan and aliphatic polyester blends," Materials Science and Engineering A, vol. 403, no. 1-2, pp. 57-68, 2005.

[5] V. M. Correlo, L. F. Boesel, M. Bhattacharya, J. F. Mano, N. M. Neves, and R. L. Reis, "Hydroxyapatite reinforced chitosan and polyester blends for biomedical applications," Macromolecular Materials and Engineering, vol. 290, no. 12, pp. 1157-1165, 2005.

[6] V. M. Correlo, L. F. Boesel, E. Pinho et al., "Melt-based compression-molded scaffolds from chitosan-polyester blends and composites: morphology and mechanical properties," Journal of Biomedical Materials Research Part A, vol. 91, no. 2, pp. 489-504, 2009.

[7] P. Lee, R. Lin, J. Moon, and L. P. Lee, "Microfluidic alignment of collagen fibers for in vitro cell culture," Biomedical Microdevices, vol. 8, no. 1, pp. 35-41, 2006.

[8] E. T. Baran, J. F. Mano, and R. L. Reis, "Starch-chitosan hydrogels prepared by reductive alkylation cross-linking," Journal of Materials Science: Materials in Medicine, vol. 15, no. 7, pp. 759-765, 2004.

[9] C. M. Vaz, L. A. de Graaf, R. L. Reis, and A. M. Cunha, Soy Protein-Based Systems for Different Tissue Regeneration Applications, Nato Science Series, Kluwer, Dordrecht, The Netherlands, 2002.

[10] N. Bhattarai, Z. Li, D. Edmondson, and M. Zhang, "Alginatebased nanofibrous scaffolds: structural, mechanical, and biological properties," Advanced Materials, vol. 18, no. 11, pp. 1463-1467, 2006.

[11] C. Li, C. Vepari, H. J. Jin, H. J. Kim, and D. L. Kaplan, "Electrospun silk-BMP-2 scaffolds for bone tissue engineering," Biomaterials, vol. 27, no. 16, pp. 3115-3124, 2006.

[12] G. A. Silva, A. Pedro, F. J. Costa, N. M. Neves, O. P. Coutinho, and R. L. Reis, "Soluble starch and composite starch Bioactive Glass 45S5 particles: synthesis, bioactivity, and interaction with rat bone marrow cells," Materials Science and Engineering C, vol. 25, no. 2, pp. 237-246, 2005.

[13] J. F. Mano, G. A. Silva, H. S. Azevedo et al., "Natural origin biodegradable systems in tissue engineering and regenerative medicine: present status and some moving trends," Journal of the Royal Society Interface, vol. 4, no. 17, pp. 999-1030, 2007.

[14] P. A. Gunatillake, R. Adhikari, and N. Gadegaard, "Biodegradable synthetic polymers for tissue engineering," European Cells and Materials, vol. 5, pp. 1-16, 2003. 
[15] J. Venugopal, P. Vadgama, T. S. S. Kumar, and S. Ramakrishna, "Biocomposite nanofibres and osteoblasts for bone tissue engineering," Nanotechnology, vol. 18, no. 5, Article ID 055101, 2007.

[16] T. Lin, H. Wang, and X. Wang, "Self-crimping bicomponent nanofibers electrospun from polyacrylonitrile and elastomeric polyurethane," Advanced Materials, vol. 17, no. 22, pp. 26992703, 2005.

[17] N. M. Neves, R. Campos, A. Pedro, J. Cunha, F. Macedo, and R. L. Reis, "Patterning of polymer nanofiber meshes by electrospinning for biomedical applications," International Journal of Nanomedicine, vol. 2, no. 3, pp. 433-448, 2007.

[18] J. V. Araujo, A. Martins, I. B. Leonor, E. D. Pinho, R. L. Reis, and N. M. Neves, "Surface controlled biomimetic coating of polycaprolactone nanofiber meshes to be used as bone extracellular matrix analogues," Journal of Biomaterials Science, Polymer Edition, vol. 19, no. 10, pp. 1261-1278, 2008.

[19] H. Yoshimoto, Y. M. Shin, H. Terai, and J. P. Vacanti, "A biodegradable nanofiber scaffold by electrospinning and its potential for bone tissue engineering," Biomaterials, vol. 24, no. 12, pp. 2077-2082, 2003.

[20] Z. M. Huang, Y. Z. Zhang, M. Kotaki, and S. Ramakrishna, "A review on polymer nanofibers by electrospinning and their applications in nanocomposites," Composites Science and Technology, vol. 63, no. 15, pp. 2223-2253, 2003.

[21] H. S. Yoo, T. G. Kim, and T. G. Park, "Surface-functionalized electrospun nanofibers for tissue engineering and drug delivery," Advanced Drug Delivery Reviews, vol. 61, no. 12, pp. 1033-1042, 2009.

[22] J. H. Jang, O. Castano, and H. W. Kim, "Electrospun materials as potential platforms for bone tissue engineering," Advanced Drug Delivery Reviews, vol. 61, no. 12, pp. 1065-1083, 2009.

[23] I. Armentano, M. Dottori, E. Fortunati, S. Mattioli, and J. M. Kenny, "Biodegradable polymer matrix nanocomposites for tissue engineering: a review," Polymer Degradation and Stability, vol. 95, no. 11, pp. 2126-2146, 2010.

[24] X. Yang, K. R. Ogbolu, and H. Wang, "Multifunctional nanofibrous scaffold for tissue engineering," Journal of Experimental Nanoscience, vol. 3, no. 4, pp. 329-345, 2008.

[25] J. S. Choi, S. J. Lee, G. J. Christ, A. Atala, and J. J. Yoo, "The influence of electrospun aligned poly( $\varepsilon$-caprolactone)/collagen nanofiber meshes on the formation of selfaligned skeletal muscle myotubes," Biomaterials, vol. 29, no. 19, pp. 2899-2906, 2008.

[26] G. B. Yin, Y. Z. Zhang, S. D. Wang, D. B. Shi, Z. H. Dong, and W. G. Fu, "Study of the electrospun PLA/silk fibroingelatin composite nanofibrous scaffold for tissue engineering," Journal of Biomedical Materials Research Part A, vol. 93, no. 1, pp. 158-163, 2010.

[27] C. Spadaccio, A. Rainer, M. Trombetta et al., "Poly-1lactic acid/hydroxyapatite electrospun nanocomposites induce chondrogenic differentiation of human MSC," Annals of Biomedical Engineering, vol. 37, no. 7, pp. 1376-1389, 2009.

[28] Z. C. Xing, W. P. Chae, J. Y. Baek, M. J. Choi, Y. Jung, and I. K. Kang, "In vitro assessment of antibacterial activity and cytocompatibility of silver-containing phbv nanofibrous scaffolds for tissue engineering," Biomacromolecules, vol. 11, no. 5, pp. 1248-1253, 2010.

[29] F. Chen, X. Li, X. Mo, C. He, H. Wang, and Y. Ikada, "Electrospun chitosan-P(LLA-CL) nanofibers for biomimetic extracellular matrix," Journal of Biomaterials Science, Polymer Edition, vol. 19, no. 5, pp. 677-691, 2008.

[30] S. I. Jeong, A. Y. Lee, Y. M. Lee, and H. Shin, "Electrospun gelatin/poly(L-lactide-co- $\varepsilon$-caprolactone) nanofibers for mechanically functional tissue-engineering scaffolds," Journal of Biomaterials Science, Polymer Edition, vol. 19, no. 3, pp. 339357, 2008.

[31] I. K. Kwon and T. Matsuda, "Co-electrospun nanofiber fabrics of poly(L-lactide-co- $\varepsilon$-caprolactone) with type I collagen or heparin," Biomacromolecules, vol. 6, no. 4, pp. 2096-2105, 2005.

[32] I. Han, K. J. Shim, J. Y. Kim et al., "Effect of poly(3-hydroxybutyrate-co-3-hydroxyvalerate) nanofiber matrices cocultured with hair follicular epithelial and dermal cells for biological wound dressing," Artificial Organs, vol. 31, no. 11, pp. 801808, 2007.

[33] W. Meng, S. Y. Kim, J. Yuan et al., "Electrospun PHBV/collagen composite nanofibrous scaffolds for tissue engineering," Journal of Biomaterials Science, Polymer Edition, vol. 18, no. 1, pp. 81-94, 2007.

[34] L. Ghasemi-Mobarakeh, M. P. Prabhakaran, M. Morshed, M. H. Nasr-Esfahani, and S. Ramakrishna, "Electrospun poly $(\varepsilon-$ caprolactone)/gelatin nanofibrous scaffolds for nerve tissue engineering," Biomaterials, vol. 29, no. 34, pp. 4532-4539, 2008.

[35] W. Meng, Z.-C. Xing, K.-H. Jung et al., "Synthesis of gelatincontaining PHBV nanofiber mats for biomedical application," Journal of Materials Science: Materials in Medicine, vol. 19, no. 8, pp. 2799-2807, 2008.

[36] H.-W. Kim, H.-S. Yu, and H.-H. Lee, "Nanofibrous matrices of poly(lactic acid) and gelatin polymeric blends for the improvement of cellular responses," Journal of Biomedical Materials Research Part A, vol. 87, no. 1, pp. 25-32, 2008.

[37] J. Yuan, J. Shen, and I.-K. Kang, "Fabrication of protein-doped PLA composite nanofibrous scaffolds for tissue engineering," Polymer International, vol. 57, no. 10, pp. 1188-1193, 2008.

[38] J. Yuan, Z.-C. Xing, S.-W. Park et al., "Fabrication of $\mathrm{PHBV} /$ keratin composite nanofibrous mats for biomedical applications," Macromolecular Research, vol. 17, no. 11, pp. 850-855, 2009.

[39] H. Pan, H. Jiang, and W. Chen, "Interaction of dermal fibroblasts with electrospun composite polymer scaffolds prepared from dextran and poly lactide-co-glycolide," Biomaterials, vol. 27, no. 17, pp. 3209-3220, 2006.

[40] G. Sui, X. Yang, F. Mei et al., "Poly-L-lactic acid/hydroxyapatite hybrid membrane for bone tissue regeneration," Journal of Biomedical Materials Research Part A, vol. 82, no. 2, pp. 445454, 2007.

[41] K. H. Lee, H. Y. Kim, Y. J. Ryu, K. W. Kim, and S. W. Choi, "Mechanical behavior of electrospun fiber mats of poly(vinyl chloride)/polyurethane polyblends," Journal of Polymer Science Part B, vol. 41, no. 11, pp. 1256-1262, 2003.

[42] S. I. Jeong, E. K. Ko, J. Yum, C. H. Jung, Y. M. Lee, and H. Shin, "Nanofibrous poly(lactic acid)/hydroxyapatite composite scaffolds for guided tissue regeneration," Macromolecular Bioscience, vol. 8, no. 4, pp. 328-338, 2008.

[43] Z.-C. Xing, Y. P. Chae, M. W. Huh et al., "In vitro anti-bacterial and cytotoxic properties of silver-containing poly(L-lactideco-glycolide) nanofibrous scaffolds," Journal of Nanoscience and Nanotechnology, vol. 11, no. 1, pp. 61-65, 2011.

[44] X. Hu, W. Lui, L. Cui, M. Wang, and Y. Cao, "Tissue engineering of nearly transparent corneal stroma," Tissue Engineering, vol. 11, no. 11-12, pp. 1710-1717, 2005.

[45] C. Yang, P. J. Hillas, J. A. Báez et al., "The application of recombinant human collagen in tissue engineering," BioDrugs, vol. 18, no. 2, pp. 103-119, 2004.

[46] Z. C. C. Chen, A. K. Ekaputra, K. Gauthaman, P. G. Adaikan, H. Yu, and D. W. Hutmacher, "In vitro and in vivo analysis 
of co-electrospun scaffolds made of medical grade poly $(\varepsilon-$ caprolactone) and porcine collagen," Journal of Biomaterials Science, Polymer Edition, vol. 19, no. 5, pp. 693-707, 2008.

[47] E. A. MacGregor and C. T. Greenwood, Polymers in Nature, John Wiley \& Sons Press, New York, NY, USA, 1980.

[48] H. Jiang, D. Fang, B. S. Hsiao, B. Chu, and W. Chen, "Optimization and characterization of dextran membranes prepared by electrospinning," Biomacromolecules, vol. 5, no. 2, pp. 326 333, 2004.

[49] A. Bianco, I. Cacciotti, M. Lombardi, L. Montanaro, and G. Gusmano, "Thermal stability and sintering behaviour of hydroxyapatite nanopowders," Journal of Thermal Analysis and Calorimetry, vol. 88, no. 1, pp. 237-243, 2007.

[50] T. Koshino, T. Murase, T. Takagi, and T. Saito, "New bone formation around porous hydroxyapatite wedge implanted in opening wedge high tibial osteotomy in patients with osteoarthritis," Biomaterials, vol. 22, no. 12, pp. 1579-1582, 2001.

[51] J. D. Bronzino, The Biomedical Engineering Handbook, CRC Press, Boca Raton, Fla, USA, 1995.

[52] A. E. Porter, N. Patel, J. N. Skepper, S. M. Best, and W. Bonfield, "Effect of sintered silicate-substituted hydroxyapatite on remodelling processes at the bone-implant interface," Biomaterials, vol. 25, no. 16, pp. 3303-3314, 2004.

[53] S. Gay, S. Arostegui, and J. Lemaitre, "Preparation and characterization of dense nanohydroxyapatite/PLLA composites," Materials Science and Engineering C, vol. 29, no. 1, pp. 172$177,2009$.

[54] W. P. Faulk and G. M. Taylor, "Communication to the editors. An immunocolloid method for the electron microscope," Immunochemistry, vol. 8, no. 11, pp. 1081-1083, 1971.

[55] E. Falletta, M. Bonini, E. Fratini et al., "Clusters of poly(acrylates) and silver nanoparticles: structure and applications for antimicrobial fabrics," Journal of Physical Chemistry C, vol. 112, no. 31, pp. 11758-11766, 2008.

[56] D. D. Evanoff Jr. and G. Chumanov, "Synthesis and optical properties of silver nanoparticles and arrays," ChemPhysChem, vol. 6, no. 7, pp. 1221-1231, 2005.

[57] M. Rai, A. Yadav, and A. Gade, "Silver nanoparticles as a new generation of antimicrobials," Biotechnology Advances, vol. 27, no. 1, pp. 76-83, 2009.

[58] J. Y. Lee, Y. Liao, R. Nagahata, and S. Horiuchi, "Effect of metal nanoparticles on thermal stabilization of polymer/metal nanocomposites prepared by a one-step dry process," Polymer, vol. 47, no. 23, pp. 7970-7979, 2006.

[59] X. J. Wang, G. J. Song, and T. Lou, "Fabrication and characterization of nano-composite scaffold of PLLA/silane modified hydroxyapatite," Medical Engineering \& Physics, vol. 32, no. 2, pp. 391-397, 2010.

[60] Y. Zhao, B. Zou, Z. Shi, Q. Wu, and G. Q. Chen, "The effect of 3-hydroxybutyrate on the in vitro differentiation of murine osteoblast MC3T3-E1 and in vivo bone formation in ovariectomized rats," Biomaterials, vol. 28, no. 20, pp. 30633073, 2007.

[61] H. J. Kong, T. Boontheekul, and D. J. Mooney, "Quantifying the relation between adhesion ligand-receptor bond formation and cell phenotype," Proceedings of the National Academy of Sciences of the United States of America, vol. 103, no. 49, pp. 18534-18539, 2006.

[62] R. A. Jackson, S. Murali, A. J. van Wijnen, G. S. Stein, V. Nurcombe, and S. M. Cool, "Heparan sulfate regulates the anabolic activity of MC3T3-E1 preosteoblast cells by induction of Runx2," Journal of Cellular Physiology, vol. 210, no. 1, pp. 38-50, 2007.
[63] E. A. Cavalcanti-Adam, P. Tomakidi, M. Bezler, and J. P. Spatz, "Geometric organization of the extracellular matrix in the control of integrin-mediated adhesion and cell function in osteoblasts," Progress in Orthodontics, vol. 6, no. 2, pp. 232237, 2005

[64] J. Y. Shen, M. B. E. Chan-Park, Z. Q. Feng, V. Chan, and Z. W. Feng, "UV-embossed microchannel in biocompatible polymeric film: application to control of cell shape and orientation of muscle cells," Journal of Biomedical Materials Research Part B, vol. 77, no. 2, pp. 423-430, 2006.

[65] K. Isama and T. Tsuchiya, "Enhancing effect of poly(L-lactide) on the differentiation of mouse osteoblast-like MC3T3-E1 cells," Biomaterials, vol. 24, no. 19, pp. 3303-3309, 2003.

[66] S. Haimi, L. Moimas, E. Pirhonen et al., "Calcium phosphate surface treatment of bioactive glass causes a delay in early osteogenic differentiation of adipose stem cells," Journal of Biomedical Materials Research Part A, vol. 91, no. 2, pp. 540$547,2009$.

[67] Z. Ge, L. Wang, B. C. Heng et al., "Proliferation and differentiation of human osteoblasts within 3D printed poly-lacticco-glycolic acid scaffolds," Journal of Biomaterials Applications, vol. 23 , no. 6, pp. 533-547, 2009. 

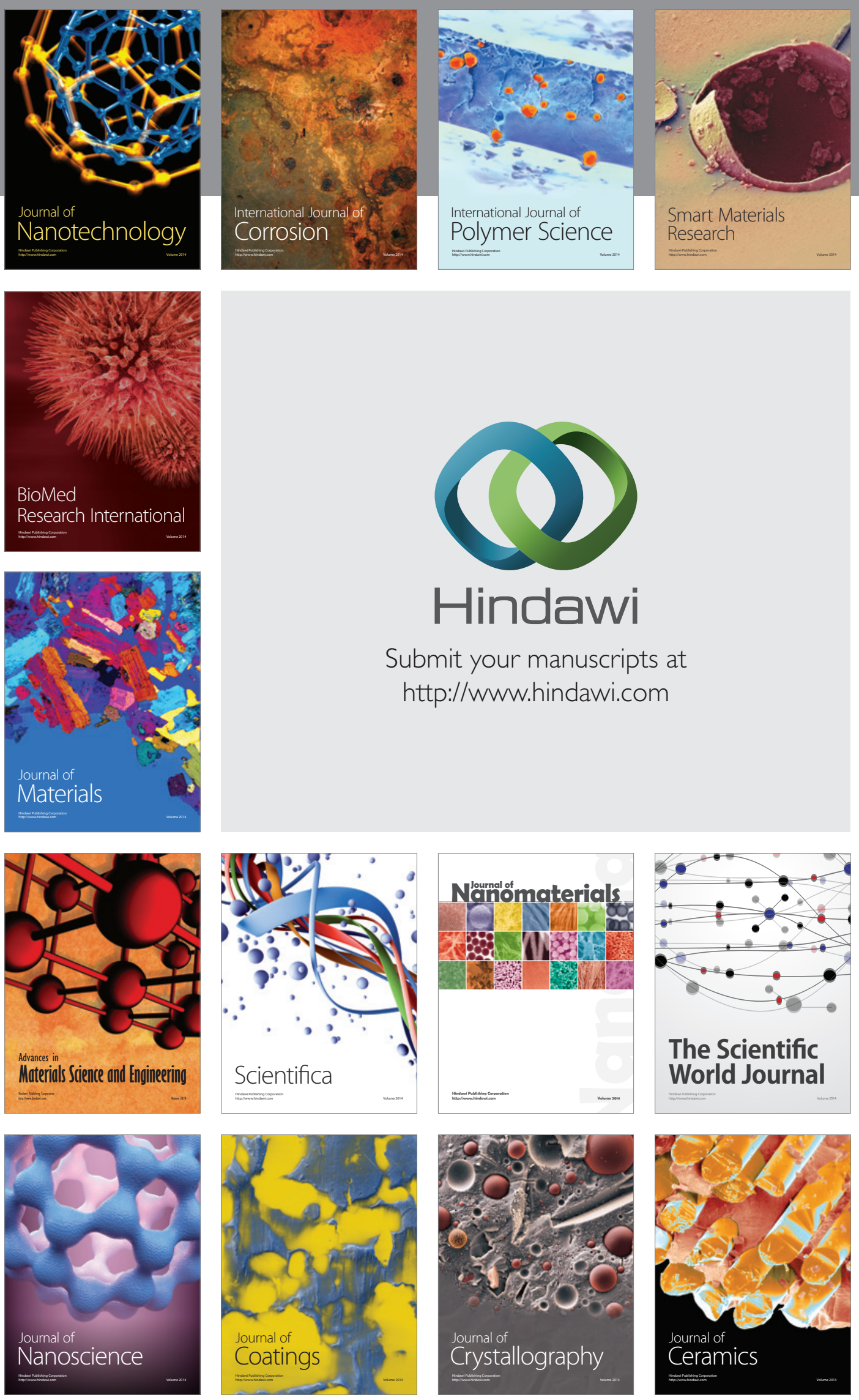

The Scientific World Journal

Submit your manuscripts at

http://www.hindawi.com

\section{World Journal}

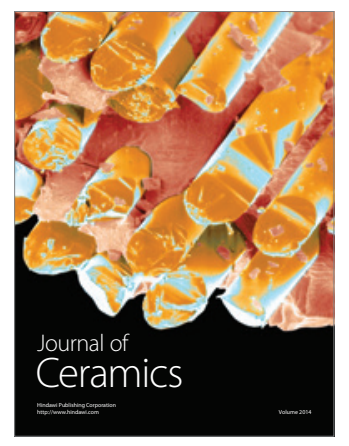

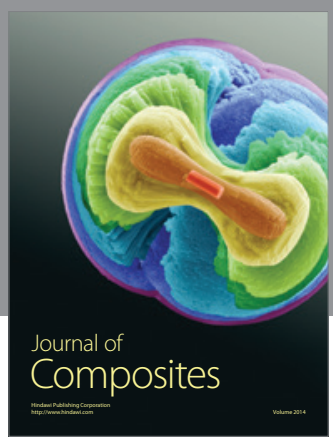
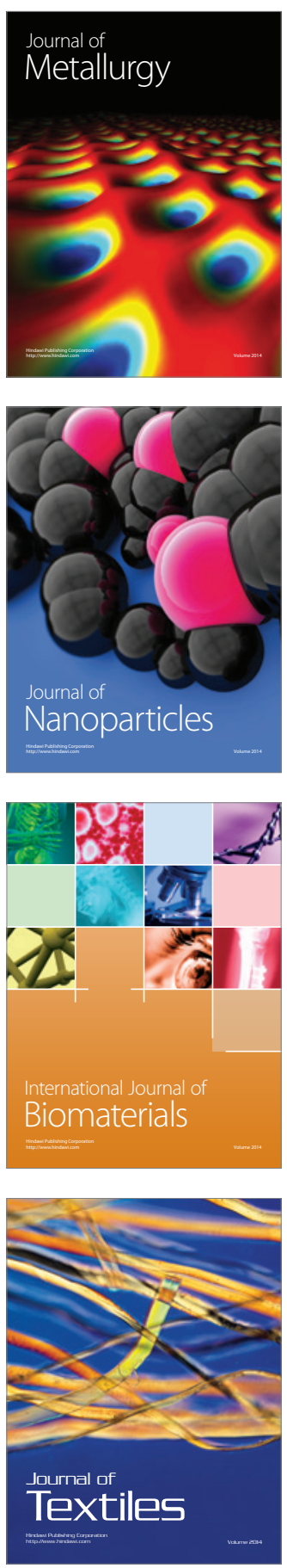